\title{
O tempora $O$ mores: Building an epistemological procedure for modeling the socio-anthropological factors of rural Neolithic socio-ecological systems: Stakes, choices, hypotheses and constraints.
}

Saqalli Mehdi, Saenz Melio, Belem Mahamadou, Lespez Laurent \& Thiriot Samuel.

\begin{abstract}
Trying to model a rural society, and even more so a past and disappeared rural society, is a dangerous task in the sense that we deal with the complexity of a whole society whatever the purpose of the model, to integrate and / or to simplify in a proper manner. This article deals with this complexity mainly by exploring the least risky way to apprehend it: starting from the question to be modelled, it is possible to gradually define the different scales, the set of variables to be considered and therefore the disciplines to be included and mobilised. Then comes only the evaluation of the data quality criteria but also of their source. We are continuing with the scheduling of modules describing the environment itself, the resource use practices and finally societal rules. Finally, we discuss the methodological, social and professional constraints in involving people in the creation of such models.
\end{abstract}

\section{Key-words}

Interdisciplinary epistemology; modelling methodology; data time quality evaluation; Neolithic production activities

\section{Introduction}

Since about two decades, researchers build models of past rural socio-ecological systems (RSES). These models are the result of the intersection of archaeology, which gathers and interprets remains of these past systems in order to understand better our past, and modelling and simulation which comes with its own concepts, methodologies and practices. The irruption of computational modelling in a domain of social sciences is never straightforward. Indeed, it has to be discussed in order to explicit and bound the epistemological role of modelling for this field according to its peculiarities and traditional methodologies such as equivalent dynamics occurring in other disciplines such as geography (Lambin et al., 2000; 2001), economics (Morgan, 2005), socio-environmental psychology (Ostrom, 1988), social sciences in general (Epstein, 1999; Gilbert and Troitzsch, 2005), sociology (Epstein, 2007), political sciences (Cioffi-Revilla and Rouleau, 2009; Montmain and Penalva, 2003).

As modelers, when we proposed to add a social dynamic inside a model of a RSES - such as the inheritance system - we often faced the opposition « we do not have enough data about this phenomenon and should therefore not describe it inside the model (or at least, do not put my name)" The "not-enough-data" assertion is theoretically always valid and the need for more data should be infinite: whatever the issue, data will be lacking unless one tends to build a 1:1 model! This anecdote illustrates the gap between sciences with different epistemologies, such as those related to the growing interactions between modeling and archaeology.

It is true a model grounded into no data would not contribute the progress of knowledge. However, computational models simulate dynamics, and might therefore be irrelevant if a component having a strong influence on the system is not described - in this case, it might be better to introduce hypotheses and question them by simulations rather than build a wrong model because of the availability of data. Behind this anecdote stand a misunderstanding about the role of the 
model. A computation model is not supposed to represent a complete and definitive theory of the RSES, but is only stands as a tool to question hypotheses by analyzing their consistency and consequences once extrapolated with simulation.

Beyond the question of data, models should be seen more as a dynamic attempt to formalize archaeological and paleoenvironmental knowledge, and also to confront and integrate these systems with perspectives from other disciplines such as agronomy, zootechnics, socio-anthropology and even more conceptual views on socio-ecological systems for instance Janssen and Ostrom (2006a, 2006b). The difficulties of collecting paleoenvironmental and archaeological data in such a way as to compare them and construct a conceptual model of Nature/Society interactions is highlighted by numerous studies. Some research identified the relationship between the difficulty of explaining the causalities of dynamics and the dependency among assumptions, scale and forcings (Carozza et al. 2015; Lespez et al. 2016). Modelling appears to be one of the solutions for exploring these complex causalities. Such modelling is thus a means of conceptualizing the dynamics within complex systems as well as serving as a testbed for addressing hypotheses that have been impossible to discriminate and determine which is dominant.

Models of RSES are not definitive proposals of theories, but more tools to help researchers to think, communicate and collaborate. This essential point being clarified, we first start this editorial article by recalling (section 1) why these models are built. The art of modelling past societies remains a recent and difficult process paved with hidden constraints, stakes and issues in terms of epistemology and methodology. We discuss them in sections 2 and 3 based on elements gathered from several modelling experiences, a mix of good practices shared among practitioners of this field and from our personal experience.

\section{What models are we talking about?}

As retraced by Gilbert \& Troitzsch (2005), the first attempts to use simulation to study social phenomena started as early as 1960 , before intensive explorations in many domains during the 1990ies. Models of rural socio-ecological systems were explored during this last, and recent, stream of studies.

Models of rural Neolithic socio-ecological systems attempt to reproduce in computers the sociological entities (households or individuals), the ecological aspects (climate, land and streams, vegetation both cropped and uncropped, fauna, both raised and not) and the relationships among them that occur under certain conditions of time and space. Such a model is necessarily made up of a patchwork of the knowledge of several disciplines. Regarding only Neolithic issues, many modeling attempts have been successfully assessed (Ebersbach, 1999; Kohler and Gumerman, 2000; Dolukhanov and Shukurov, 2003; Janssen et al. 2003; Ebersbach and Schade, 2004; Hazelwood and Steele, 2004; Janssen and Scheffer, 2004; Allen et al. 2006; Kohler and van der Leeuw, 2007; Altaweel, 2008; Janssen, 2009; Lemmen et al. 2009; Tipping et al. 2009; Patterson et al. 2010; Graves, 2011; Kaplan et al. 2012; Kohler et al. 2012; Lemmen and Khan, 2012; Yu et al. 2012; Carrer, 2013; Baum, 2014; Saqalli et al. 2014; Lemmen and Wirtz, 2014; Bernabeu Aubán et al. 2015), among others, which the study of Saqalli \& Baum (2016) sought to characterize according to scale and conditionalities.

This type of model is often built following a spatialized modelling approach with many pixels as pieces of land and many entities, called agents, as households or occasionally individuals: with only pixels, such distributive models are referred to as cellular automata; with agents, they are referred to as agent-based models. In the latter, the various entities and components of interest in the sociotechnical system are explicitly represented in the model. They might be represented with different levels of granularity: for instance, sheep might be represented as individual sheep or as herds; individuals might be grouped into households or individualized. All of these entities are spatialized in the environment, meaning they have a location in the simulated environment, can often move, and are able to perceive and act on it. The environment is most generally discretized and represented on a grid. The behaviors of each entity and of the environment are modelled together and thus at the same scale, for instance, $1 \mathrm{~km}^{2}$ or 1 ha or more, as well as the interactions among the entities and 
among the entities and the environment. Entities "live their lives" during the simulation, along the same time pattern and therefore along the same succession of timesteps, of one week, one month or one year; during the simulation, they move in the spatial environment as they are thought to do. All these models can be considered to be KIDS (Keep It Descriptive, Stupid!) models (Edmonds \& Moss, 2005), meaning they are literally designed to describe the overall dynamics. Results of such models eventually contradict hypotheses, obtaining surprising or counter-intuitive findings as a result of such intricate and complex sets of processes. We position our conceptualization of modelling following van Gigch (1993), Batty and Torrens (2001), Bouleau ( 2001), Beven (2002), Couclelis (2002), Kieken et al. (2003); Boero and Squazzoni (2005), Franck and Troitzsch (2005), Lake (2015), Rodgers (2016) and Schulze (2017).

\section{Why models are used for apprehending Rural Socio-Ecological Systems (RSES), both past and present-time ones?}

Whilst the usage of computer models might seem to be a novel methodology at first glance, archaeologists already model without computers, meaning they construct hypotheses and theories from collected obtained data. This demarche, or modality of inference, often called "inductive" in the most accepted hypothetico-deductive research, i.e., deduction, induction and abduction (Blecic and Cecchini, 2008), implies the overall combination of "elements" or pieces of science along a plan that may enlighten an issue to be confronted with other facts for validation. In the past, this may have been assessed in an intuitive process, such as that described by Bergson (1911): he described this capacity of connecting processes, patterns and dynamics along sometimes illogical analogies, comparisons and consistencies as a purely human action, which is impossible to formalize. As a consequence, a first reason for using computational models is just that as any scientific domain, archaeology produces, encodes and communicates theories; computational models are just one type of such a model among others.

A model is a simplification of a system built to help an observer to answer a question on the system (Minsky, 1965). Models are encoded using a symbolism (Minsky, 1965; Ostrom, 1988), which comes with methodological and epistemological benefits and constraints. Models encoded as mathematical equations are not ambiguous, are compact and can therefore be used to communicate theories easily. Using deduction, they can sometimes extrapolate theories to produce novel knowledge, such as to prove the states a system can or cannot be reached, or that a representation of a system is consistent or not. Unfortunately, mathematical modelling has a limited expressive power, especially when it comes to model complex systems made of entities in interaction (for instance, mathematics cannot capture dynamics simulated by even simplistic cellular automata; Wolfram, 2002). Discursive models encode knowledge and theories in the form of natural language, and have therefore unlimited expressive power, but are more verbose and remain as ambiguous to transmit knowledge as human language in general (Eco, 1990). On expressive power, computational models offer a trade-off between discursive and mathematical models (Ostrom, 1988; Taber and Timpone, 1996)); they can be used to describe systems made of spatialized heterogeneous entities in interaction.

Discursive models do not help scientists to directly generate novel knowledge; once written, the words do not produce novel words which deduct consequences from the written premises; in other words, discursive models allow encoding and communicating theories, but do not produce novel knowledge as a mathematical proof would. If they do not provide any mathematical proof, computational models can be explored by simulation, which computes the evolution of the system in time according to the rules which were encoded inside them; this generative power, as named by Epstein (1999), was said by Axelrod (2006) to constitute a third way to do social sciences. Simulation produces knowledge because it helps researchers to discover the consequences of the theories they encoded. These consequences often might be obtained only by simulation and would not have been reached just by reasoning. Various reasons explain this fact: computers can simulate the consequences of simple rules on many entities, which is beyond the capabilities of the human brain (as for the 
rules for forecasting meteorological previsions are relatively simple but only can be computed by powerful computers). Sometimes the chaining of the consequences of loops might create complex and non-linear interactions such as bandwagons, cascades of effects, reinforcement loops and/or cyclic dynamics such as the well-known Lotka Volterra dynamics. Sometimes the local behaviors described by the modeler create phenomena of an upper order of analysis (segregation our simple local preferences; traffic jams out of the behavior of cars) which is said to be emergent (Deguet et al. 2006). The second motivation for the usage of models for the study of RSES is thus the fact computation models generate knowledge (Epstein, 2007), as they help us to assess the consequences of our theories.

The interest in modelling tools for collaboration, especially when implemented to integrate both qualitative and quantitative information and rules, is that they are more neutral and balanced, limiting ideologies, preferences and bias due to the obligation of explicit and written formalization of rules: findings are transparent and can be checked and discussed among a community of researchers (Etienne, 2010; Etienne et al. 2011).

Another motivation for the use of models is that it is simply convenient: as stated by Kohler and Van der Leeuw (2007) in their introduction to "socio-natural models," the modeling approach helps to go beyond the narrative description of a society of many archaeologists by avoiding ambiguity and including complex rules beyond simple and deterministic linear connections among elements, usually humans and resources. With regard to this point, we take a social constructivist view of considering societies (for instance, the values, ways and practices by which a society use is contextually defined, which may vary among societies and within them because they are produced by the society itself, opposed to essentialist perspectives), but as a more essentialist way of regarding physicality, meaning that we consider the constraints that limit and determine rural societies, both directly (such as the ecological productivity of a territory regarding a set of techniques and social practices) or indirectly through, for instance, demography. Therefore, if social laws can be considered in terms of our own mental constructions (unless a right has been written or edited), agro-ecological laws are "real", meaning that imitating them or following them (according to the epistemological position one may have, either constructivist or essentialist respectively) is not the purpose of a model focusing on RSES: we take law of Biology and Physics for granted.

Finally, unlike already-fitted theories, models can improve themselves: As other experiments, they can serve as a step-bystep trial/error demarche. The production of knowledge is not one shot, such as collecting data / creating theory explaining observations / collecting more data. Experiments with the model also raise questions, contradict theories, or raise difficulties. Actually, we do agree with this: such rules are difficult to settle as each of them may imply many factors and not merely one or two for each side. For instance, the land use of a 1-ha pixel by nearby villagers may be settled in models according to distance to houses, local pedology, local cover as well as the food requirements and manpower availability of each household using this land according to each household local rights-to-use, each factor having its own dynamic with stochastic variations. Selecting and testing which approach best fits with the external data is a fully acceptable way of using progressive model improvement.

\section{Difficulties in the construction of a model of RSES and outlines}

However, because such rules imitate or follow reality, they are all complicated and are thus difficult to construct as a group of variables linked together, then as a parameterized formula and finally as a parameter-numbered rule. Moreover, one should first define to which entity such formula should be applied: for instance, applying an inheritance rule to a family has different consequences than to an individual: the former introduces the distribution between direct and indirect descendants while the latter may describe inheritance differentiations between direct ascendants, such as gender or geniture discrimination, which are necessary for all social stratification reconstitution. The same is valuable for the scale of 
the model, for instance, between a pixel of $1 \mathrm{~m}^{2}, 1$-hectare or $1 \mathrm{~km}^{2}$, which determines the level of details for agricultural activities. The explored issue is then that which determines which scale and which entity level should be selected.

More globally, we see here how complex it is to delineate the issue of what we want to model, and for what, before even engaging in actual modeling. The following questions must be applied when building a modelling methodology:

- Can the model answer the questions that are posed? Before that, how can such questions be raised among a community of researchers with various issues, focuses and questions?

- Can the interdisciplinary pattern and the hierarchy of disciplines be defined? Further, can variables be defined according to criteria that extend beyond the traditional but scientifically questionable in that they are derived from the socially based "gentlemen's agreement" as constructed above?

- Can the model comprehensively explore the various elements to be taken into account while modeling Neolithic rural socio-ecological systems?

\section{Arguments for rural socio-ecological systems' distributive modelling}

\subsection{Interdisciplinary approach: why using it?}

Several points plea for interdisciplinarity (Porter et al. 2006; Saqalli et al. 2017) in the RSES study:

"The best complexity": RSES, both past and present, structurally include many disciplines, for instance, one cannot understand livestock keeping without zootechnics, geography and anthropology: it is not a question of the methodology to be chosen, it is the object itself that drives the inclusion of these disciplines. Sometimes, such disciplines are eliminated because of a lack of data, which creates objects that are impossible to understand. More precisely, we hypothesize that considering all components of a RSES, including those that come from society, environment and economy and that simplify each component, to be more reliable and less harmful in terms of understanding than neglecting some activities and focusing on those that seem to be the most important and/or on which data have been obtained ${ }^{1}$. For instance, modeling a Lotka-Volterra predator/prey system (Neuhauser and Pacala, 1999) without modeling the predator because of a lack of data regarding its ecology would just lead to a population of prey growing as much as resources enable it, without cycles in the population sizes due to the competition between both species. In such a situation, it would be more relevant to integrate a theoretical predator, even if its properties are unknown and require several parameters. One may suggest waiting until enough data are obtained. However, some situations may not allow such a hope: for instance, simulating ancient societies without integrating socio-anthropological rules of inheritance is also useless; however, one may not hope for new information apart for certain clues due to, for instance, differentiated graves.

Systemic approach: More globally, following Verburg et al. (2004), the observations are bound to the extent and resolution of the measurement generated by each observation to provide only a partial description of the whole land-use multiscale system. Beyond the scale of analysis, for instance, the land use change, it means that scientists and stakeholders must tear down the walls of the disciplinary approach and cultural context that lead to a subjective misinterpretation about such phenomena. For instance, analyzing socio-ecological processes, one of the most complex interdisciplinary scientific objects,

\footnotetext{
${ }^{1}$ Because interactions are not instantaneous, there is of course not a perfect adequacy among all interacting elements in a single timestep, and the system consistency postulate may be valid only along the simulation and not for one timestep.
} 
combining social and biophysical sciences, the complexity of it must be tackled through the study of the systemic character of reality.

"For the greater good": Indeed, the main quality of social and environmental formalization, and by then a "loud and clear" formalized interdisciplinarity, is to drive scientists and scholars to work collectively to build a common scientific object. For instance, reconstituting a livestock herding society implies working together among climatologists, zootechnicians, farming systems' specialists, socio-anthropologists and of course paleo-environmentalists and archaeologists, each one "forced" to sacrifice a portion of the complexity of their own themes on the altar of the combination of disciplines. The importance of encouraging the success of the object as a whole, and not solely one's task in isolation is crucial as is the legitimacy of the objective and the people involved. The goal of a mediation tool, such as the current model, is to "push" each member to look after the consistency of the interacting system, taken as a whole, such as the example of a livestock-keeping society, for instance, rather than the consistency between one thematic in itself: looking for inconsistencies or even impossibilities within the system is then a good way to test the common understanding over an RSES: for instance, in Saqalli et al. (2014), the impossibility of feeding the quantity of livestock necessary for producing enough manure to keep permanent fields and not shifting fields as suggested by palynology in Linear Band Keramik farming systems allows the research team to propose a systematic pruning practice as the sole practice that will be sufficiently productive.

Exactitude: accuracy vs. precision: Following the previous point, interdisciplinarity is a test for scientific rigor and, more specifically, accuracy. Accuracy is often confounded with precision (Becker, 1996), and while precision has this shiny power of data with several figures after the comma, accuracy can be settled only through a reference to a reality, a reference that is difficult to establish independently from these data. But following the metaphor of a target, how useful to send plenty of arrows within a very small range but far from the center? Therefore for instance, what do such figures mean for cases such as, for instance, demographic analyses without including migration? It often happens that scientists present their datasets without justifying the origins of the variables on which and how the data were collected. Why were those data chosen over others? We should then differentiate between variables and data and by then, characterize the scope of the object of research, i.e., its accuracy, before addressing precision. Variables allow relationships and dynamics to be obtained while data parameterize such relationships and dynamics. As a result, we can then define exactitude as the combination of accuracy and precision.

Epistemological formalism: Again following the previous point, these variables must be identified and classified according to a paradigm or a principle (or as a local expert perceptions agreement that may be accepted as a legitimization of their selection to the detriment of other variables. We do suggest as a consequence of the formalization of the criteria the principle on which they are designated as relevant. Along the flow back and forth between induction and deduction, there must also be "de jure" fair criteria for "validation".

Plausibility: Along with this formalization necessity as the second mandatory part of the research process, formalizing elements is protection against self-focusing scientific approaches such as, for instance, the classical self-checking loop mistake where a set of data, for characterizing and "validating" a phenomenon, is compared to the very same data that created it.

We may consider that "validating" a function from one scientific discipline with data from the same discipline has many more risks to create a similar loop. We then plead for steps of "validation," which implies using sets from other disciplines to lower the risks of such loops. The complexity of RSES is not inherent in a specific discipline or a domain. An interdisciplinary approach must avoid all reproduction of domination and should - ideally - transcend the frontiers of each 
discipline. Youngblood (2007) explains that "what interdisciplinary studies can therefore learn from the bridging disciplines is the importance of not becoming a domain, as domain creates territory and territory creates niche dominance [...]". As human beings, researchers act - in a certain way - like non-human animals. Ethological studies discuss social animals in a hierarchical community. We have the alpha, the beta and the omega, which interact and fight for a social position and/or the recognition of liability within a territory. Perhaps researchers should think about "a discipline" outside of disciplinary boundaries."

\subsection{Why using agent-based models for the spatial reconstruction of interactions of RSES?}

A model is first of all a simplification of something, usually a chosen portion of reality (Minsky, 1965). It is designed to answer a limited number of questions (Mazher, 2001). The first interest in modeling a dynamic, a territory where societies and territories interact is first of all to agree among researchers from different disciplines on a conceptual model that is fundamentally interdisciplinary with regard to the subject under consideration, which is not obvious. Any model is therefore also a tool for dialogue and confrontation among disciplines (Ducrot and Botta, 2009; Maru et al., 2009; Etienne, 2010).

The spatialized agent-based models used for Neolithic studies thus far have been composed of agents acting over a grid composed of cells, each entity type described by rules, with more or less complex behaviors according to the specifications of the modeling team. The benefits of these models are numerous for reconstituting the interactions between man and the environment in the past:

- Spatialization: Such models provide an account of the territory and its functioning, including the fact that a local combination of various parameters creates de facto favorable or harmful situations that are not obvious (e.g., fertile soils or rivers with no access to water in summer because of karst rocks).

- Interdisciplinarity: Such models are very flexible in answering a question but "oblige" not to neglect environmental or social dynamics without which the model will not work (e.g., rules of commensalism in the case of famine: who eats first? Also relevant is the functioning of a possible transhumance or the collapse of local pastoral resources).

- Entity-specificity: Because these dynamics are formalized at the scale of the acting entity or undergoing the dynamics, the approach is more intuitive for monodisciplinary scientists involved: it is easier to determine a parameter for a family than for a population, the latter parameter being the result of the first combined with many other variables. However, it allows us to see interactions on a very local scale (e.g., the combination of drought, soils that have become poor and a small adult population will create local famine and not elsewhere).

- Adapted to qualitatively based low-data issues: These tools, by means of the rules introduced to simulate the behavior of family agents, for example, make it possible to integrate qualitative rules with a significant quantitative importance (e.g., patri- or matrilocality, ultimo or primogeniture). More generally, they make it possible to simulate the "noise" of societies (the fact that not all rural populations do necessarily do the same thing) and, by using rules based on the literature, the experience of experts in a field makes it possible to manage the quantitative weakness of data, which is the main difficulty inherent in any reconstruction of the past.

- Nothing on the multi scale, multi-level aspect? Do models enable us to link what we know at the scale of the entity with what can be explored at a broader scale thanks to simulation?

\subsection{Finding the equilibrium between simplicity and complexity for modelling past societies}

- The longer the simulation is carried out over time, the more the simulated society evolves and therefore the more the model must be generic and increase in abstraction to mimic these evolutions. The same should be applied for cases of 
ecological variety. Therefore, for more validity, it is better to somehow restrict the genericity of all models, for example, a terrain as ecologically homogeneous as possible and a short simulation time.

- The defects and qualities of simulation models are faces of the same coin: they open up many possibilities but close few. However, a benefit of the models is their efficiency, such as when they are used as an experiment bench and in experimental approaches, over and above epistemological comments and debates, which first of all implies invalidation since one cannot prove that something is true but only that something is false (Popper, 1985; Carley, 1996; Brenner and Werker, 2007; Schutte, 2010). However, the more complex and less deterministic a model is, the less we may be able to invalidate something, which is the only way to go beyond gaining confidence in our hypotheses, which is a not a clear-cut gain. Therefore, the less a model is developed in terms of rationality, the better it is.

- Exploring the history of cultures and societies necessarily implies the simulation of many agents and therefore of a large population, first of all simply to obtain significant results. However, the more complex AND numerous the agents are, the slower the model will be, and the more likely it is to crash. For practical reasons, model simplification is required to be able to exploit it.

- However, we are stretched between the target of simplicity and an attempt to explore the consequences of complex rationalities. Moreover, the decomposition of these rationalities creates uncertainty about the understanding of the final result. Reducing the rationality complexity may reduce the magnitude of the results but allow their exploration.

- Obviously, we come up against the unpredictable aspect of certain major social movements, such as political conflicts, or major qualitative leaps, such as technical or social innovations, unless we introduce the drivers of these innovations and changes, which will be difficult to establish.

However, simplicity in itself risks bringing nothing out of tautologies:

- Thus, showing in a model that a hydro-agricultural society disappears when water has also vanished is not particularly remarkable. To show that such society could survive there, if only for a while, would be of greater interest because it is counter-intuitive; however, modelling the simulation showing this result implies greater complexity in the model.

- Complexity, particularly in the social sciences, allows emergence phenomena to appear. This "small causes, large effects" aspect is often the main contribution of non-environmentally focused modelling. Therefore, a good model is defined according to the target; however, it obtains counter-intuitive results due to emergent dynamics because it opens new perspectives and enlarges RSES possibilities;

- The complexity and in particular the precision of the description of phenomena at the interface between society and nature in space and time, such as the stages of the agricultural cycle and their variability, also makes it clear that practices are highly variable and adaptable to environmental variability, but they are also related to past conditions and dynamics, i.e., time inertia. However, almost always, the available data, if accurate, are not at the precision scale of the farmer and his rationality (Alam et al. 2010). Pushing complexity to this relevant scale is the only way to capture this variability and adaptability. Thus, the same simulated culture can thereby adapt itself to several different environments without the need for "forcing" through the introduction of explicit rules.

\section{A series of checkpoints before modelling take-off}

For the purposes of clarity, we use "variable" to designate the factor itself ("parameter" can also be used). We adopt this term for its validity and relevancy in answering issues that are addressed in a model as opposed to "data", which we use to designate the numerical values of such variables. 


\subsection{Building the research question: OSQHYT}

In this section, we aim to formalize the argumentation according to a series of questions. These questions are designed to clarify the purpose of the model and thereby its task. Indeed, we have observed on several occasions that, surprisingly, when model construction is successful and scientific partners see the first simulation outputs induced during implementation, they obtain an extension of their purpose beyond their initial goals. They may even arrive at a distortion of such goals in relation to their most powerful and/or dominant partners. We propose the following acronym for this formalization: OSQHYT:

- Object: what is the territory and/or the population to be implemented and in what order? This will, for instance, define the scale of the model or the level of spatial and temporal precision at which the model should be built. For instance, a model of the Linear Band Keramik (LBK, also named rubaneous culture), culture should clarify whether the aim of the model is to reconstitute the functioning of the LBK village or the dynamics of LBK expansion, which are two different tasks and therefore require two different scales. For illustration purposes, we keep on this LBK example.

- Subject: The model subject defines the part of the object to be explored, distorted and subject to testing, while the rest should be considered as ceteris paribus. For instance, one should clarify the distinction between territory and society as the first induces a model procedure based mainly on paleo-environmental data as inputs in explorations on a society with tests based on archaeological data, while the latter implies reliance first on archaeological data as inputs with tests based on paleo-environmental data. In that case, we may choose to work on the social component of the RSES, with a focus on its spatial adaptability and temporal variability.

- Question: The main issue of the model should be clarified with a question that should end with a question mark and that can be answered with a yes or a no, of course with conditionalities and restrictions. In the current study, for example, one can ask the following question: do the RSES we conceived, including its adaptability based on a sequential rationality following a system of decreasing preference, adapt and correspond to the LBK ecological, spatial and temporal distribution?

- Hypothesis: This step is the procedure for obtaining a test on our question. In our case, we make the following hypothesis: does this RSES fit with the large variability of archaeological LBK sites and with the century-long presence of certain sites?

- Test: This easier step, once the hypothesis has been obtained, is to propose a formulation of the model's methodology. To avoid the very convenient but less formal temptation of constructing an RSES, which is inconsistent in terms of zootechnics, agronomy, fishery and agroforestry in terms of its fit with spatial archaeological data, two methodologies can be considered:

- We can build a farming system with environmental preferences according to RSES rationality as deduced from the same era/ecosystem hierarchy of $\S 3.1 .2$ and therefore from the archaeological spatial data. We then compare the resulting simulation outputs with the distribution of sites.

- We can propose to select a representative portion of these spatially positioned data to deduce LBK preferences in terms of topography, soils, hydrography, and spatial organization and to test the construction of the RSES based on archaeological data and inferences from other sources following the era/ecosystem hierarchy (see $\S$ 3.1.2.) with the rest of the spatially positioned data.

We therefore obtain a complete methodology by addressing the relevant issue until the experimental testing is conducted using our simulation model. 


\subsection{Circumscribing the model drivers: AVID: Accuracy of Variables then Inventory of Data}

The problem raised here relates to the recurrent observation that the way in which an RSES-related question is asked is often determined by the availability of data. Thus environmentally deterministic explanations to any archaeological change are often used because it is indeed the only available data. This tendency looks like a chef working only according to what is in the refrigerator: the problem is not posed in such a way as to answer the scientific question as well as possible (regardless of the value of such result) but rather to answer with what one has. This way of doing things is, after all, pragmatic; however, it raises a serious issue: how can we overrule reasoning if we only give priority to the components upon which we have data?

We hypothesize that a primordial $\left.\right|^{2}$ qualitative approach, consisting first of defining which variables are to be considered and then obtaining progressively precise results through the evaluation of each of the components of the system considered, can be more scientifically valid in apprehending a scientific issue for which the variables are numerous, as in the case of environmental health issues at the interface between society and nature. This is why we propose as more scientifically valid the search for variables that are essential and primordial before providing such variables in the data once the consensus on the variables to be studied has been reached.

Once the previous point has been set, how does one choose which variables to study and what to measure?

A priori, it is possible to consider testing each variable considered and possibly overturning its importance by setting up an appropriate experimental protocol. However, by listing the variables, do we risk excluding important ones a priori, without being able to justify that we were not mistaken? According to Popper (1985), it is precisely not theoretically possible to prove that a variable must be integrated into a problem and can only be invalidated. Thus, what should we do about questions, especially on issues between society and nature, where the number of variables to consider is immense?

A protocol must make it possible to establish in advance the list of these variables to be collected and whose repetition will form the data to be analyzed. The use of variables based on "common sense" or "experience" often fails to "sort" variables by default without specifying how they are selected. In practice, we assume that, in the case of past RSESs, there are only three ways to justify which variables to study:

1) An approach based on its own positioning and its own experience "based" on a more or less recognized expertise, often justified by a publication. This often happens but induces biases;

2) An approach that uses the existing literature on the issue through reference publications usually based on Method 1. Justification is rarely provided for the factors chosen;

3) An approach based on the consensus of the scientific experts' community on the issue, which is technically equivalent to 2). This approach may be formalized through the presentation of a survey or meta-analysis of scientific articles in the field or through formal methods that co-construct the issues (Etienne, 2010; Etienne et al. 2011).

\subsection{Required qualities of variables and related data: EGI PER PRECIUM}

We tend to build a commonly agreed-upon set of criteria that may classify the value of data and sort them, based on the acronym EGI PER PRECIUM ("I acted according to value" in a very poor Latin). The definition is initially a first census from Saqalli et al. (2018) and, although independently conceived, it is similar to that of Pipino et al. (2002) and Batini et al. (2009):

Expressive, Generic, Inter-comprehensive / Perennial data sources, Efficient sensitivity, Robustness / Discriminative, Entangled, Precise, Rustic, Exact, Covering, Integrative, Useful, Measurable. We categorize these criteria in three blocks:

\footnotetext{
${ }^{2}$ Primordial in its etymological meaning : the primary one.
} 
Social and communication usefulness:

- Expressive: Variations of this variable should be easily talkative in terms of trend visualization. For instance, the $2^{\circ} \mathrm{C}$ level as a threshold for climate change is more talkative than an MW-based representation;

- Generic: This indicator is not field-dependent: it can be constructed from various sources and measurement tools and thereby can be produced from various environments, ecosystems and study sites;

- Inter-comprehensive: indicators and variables are to be understandable or at least as non-polysemic as possible given the various disciplines involved in the modeling process to avoid misunderstandings;

Sensitivity/robustness:

- Perennial in its data sources over time;

- Efficient and discriminative sensitivity: a variable may seem essential, and the corresponding data are excellent; however, if it does not influence the socio-ecological system either in space, time or in the variability of these two elements, or if it influences it but equally and homogeneously, then an equal influence is equivalent to no influence at all, and it is useless;

- Robustness of measurements: the data value is robust and trustworthy regarding the quality of the measurement and/or the operator;

Data and variable efficiency:

- Precise: the atomic entity (i.e., the smallest and inseparable unit of the model) should be as small as the constraints of the model allow and as the model issue requires. The atomic entity concerns the spatial grid pixel scale, the temporal rate of time and the socio-economic survey unit (family or individual);

- Rustic: the variable does not need complex requirements and calculations before modeling and can be used as directly as possible. For instance, precise data, such as pedological horizon heights, should be adapted in terms of the flux to be used;

- Exact: the variables should integrate the complexity of the studied elements and the reasons for why some variables in its composition have been neglected should be relevant, which is also valuable for the exactness of the related variability and differentiation according to local differences, such as agro-ecological conditions. For instance, the food gathering capacity per pixel implies components such as mushrooms, nuts, and fruits. Having good values for only fruits and nuts without mushroom data is less valuable than a rough but closer estimation;

- Covering and complete: the variable should obviously cover the whole modelled territory and the whole simulated period and no parts of time and space should have zero value.

- Integrative: the variable should allow a simplification by covering a large domain and its value: for instance, building one value for all gathered non-timber forest products is simple as far as it adapts well to seasonal and spatial variabilities;

- Useful, practical: the variable should be quantifiable and measurable. For instance, qualitative rules should transform family dynamic functioning into calculable and modelizable functions;

- Measurable: the access to the data should be simple and as free as possible.

\subsection{Where to gain access to an extinct society without written documents?}

\subsubsection{The relevant modelling unit}

Several possibilities can be envisaged to simulate human entities, all of which are related to the investigated issue and, therefore, the scale and the considered functioning regarding migrations and land use are as follows: 
1. Individuals: This component allows for the simulation of intra-family tensions and changes and therefore all inheritance transmission, gender or age discrimination and family organization variations as described above, hence the possibility of considering "cultures" whose adaptation is more or less rapid. However, this requires the formalization of intra-family rationalities on which little information is available; nevertheless, it imposes an enormous number of human entities, each corresponding to a single individual, which is difficult to manage beyond single village levels.

2. Families: This intermediary entity does not allow for the explanation of differential adaptations to the environment by the family organization. However, it can envisage inter-family differentiations on which assumptions about differentiated migration among families can be made. One can consider that this allows an "economy" of entities with a ratio of 1:5 to 9 in relation to the "individual" entity.

3. Villages: We can consider this fixed entity as creating other villages. It is possible to create the attributes "number of families" or "number of individuals" but not "records" of family dynamics, which means that it is impossible to discern families and even less so individuals and thus no differentiation between these entities in their use of the land's resources: it would be the village as a whole that would evolve. However, this scale is relevant on the global scale for entities such as continents. One can consider that this allows an "economy" of entities of a ratio of 1:5 to 20 in relation to the "family" entity.

\subsubsection{Rationality and structure of the social component of socio-ecological models}

Any variable needed for modeling the social component of RSES, past, present and prospective can be used to address rationality regardless of whether it pertains (that we may define here as the capacity, always limited, to make choices between practices, activities and social mechanisms, including norms and rules) or not according to the explored issue. If variables are used without rationality are equivalent for the past and the present (demography, for one generation, whatever the source from which they come and the way in which they were obtained, is based on equivalent dynamics as they have the same impact on population growth and structure), introducing rationality (for instance, determining the strategy used by farmers for their farming practice: maximization under constraints, securization, maximal diversification), it creates a larger and more obvious differentiation between present-time and past models: there is nobody to interview to gain access to the rationality of people, and these rationalities should be guessed.

Obviously, as with Hamlet and the skull of Yorick, one may complain about the lack of communication from such remnants: no interviews can be assessed from anthropological investigations; however, the information provided by such remnants is necessary as only such rules can directly characterize family and society dynamics, and these last components are necessary for reconstituting the functioning of societies: what are the marital practices (polygamy or monogamy?) or the inheritance transmission practices? What are the various and differential rights-of-use? What are the rules regarding manpower and resources 'organization and affectation within families and between families? What are the colonization practices, meaning, what pushes people to leave? What criteria do they use to choose a new place? Through what ways did they leave their place of origin, through individual families and/or groups? Admittedly, few quantitative data can be obtained in present-time models as well through, for instance, the analysis of socio-economic questionnaires.

Of course, quantitative data are also needed to reconstitute the structure of these societies, such as Gini indices regarding wealth as well as family size and the allocation of resources among sub-groups. One may obtain quantitative proxies of some parameters through archaeological indices, such as the number and organization of poles delimiting house size, which is considered to be a proxy for the of people living in the household.

The degree of complexity to be considered for the behavior of human entities depends on the purpose of the model and therefore on the macro-observation scale. Too many inter-agents allow behavior to be mimicked in a manner that is similar 
to that assumed but do not allow either explanations of the hypotheses chosen in a manner that is sufficiently short for publication or a full sensitivity analysis given the large number of parameters (Chattoe, 2000; Amblard et al. 2006).

Several syntheses, such as those from Verhagen and Smit (2003), Axelrod (2006), An (2012), Jonker et al. (2013), Livet et al. (2014), Malawska and Topping (2016) or Abar et al. (2017) formalize the dilemma between social relations and the complexity of agents' rationalities. The more complex an agent is, the more its behavior must be justified because any rule introduced to optimize a function can establish different forms of "forced" behavior, each applicable to the different functions of an agent. Establishing hierarchical mechanisms can help in addressing the complexity of the problems to be controlled and even reduced. As a "Primum non nocere" principle, we propose to follow a sequential behavior: "People do what they have to do when they have to do it": An example may illustrate these positionings:

1. A model for describing farming systems may be voluntarily restricted to reproducing crop cycles and other resource allocations throughout the year. The objective is to obtain the apparent reproduction of the different actions, by making agents simply reactive: "Farmers and other users use resources at a particular time and by a particular means", without an assigned objective. They do the things we want and we observe results at a more global scale to see if it fits with archaeological data.

2. Finding the reason why people were doing such activities in such ways means introducing hypotheses about objectives that are supposed to be used by these actors, their rationality. The point here is to try to imagine why cause-and-effect sequences are used. These objectives can still be made as basic as possible: "Farmers and other users manage their means of production to best achieve their objectives, namely to eat throughout the year".

3. Exploring the space of parameters of these rationalities, the spectrum in which these rationalities and practices can adapt themselves requires the implementation of prospective scenarios and in archaeological cases, scenarios mean other sites and environments and contexts (introduction of norms, innovations, social or institutional changes, new territories, etc.) leading to the definition of conceptions further upstream: "Farmers and other users seek to achieve their respective objectives by negotiating with the already settled rules, by practicing various activities and managing them". And so on, the reasoning is refined to move from reaction to cognition, from simple to complex, but also from information directly resulting from data to the translation of hypotheses about behavior and rationality.

Advantages of the first approach are two-fold: it is simpler to settle and then to explore and results are robust facing threshold effects introduced by any artificially-assumed optimization function as well as the fact that it is unassailable in terms of data suitability.

\subsubsection{Hierarchy criteria for seeking rules of the social component of socio-ecological models}

In any case, for both structure and dynamic variables, the social component of past RSES can only be guessed by borrowing information and by adopting rules from external sources. One should then construct a hierarchy of the validity and legitimacy of these sources; for the current study, we propose a hierarchy based on the proximity to the concerned RSES. Again, we take the view of simulation as nothing but an eternal source of fruitful errors, producing asymptotically improving representations of reality but never reaching it:

For the rules regulating the social component itself, the following should be noted:

1. "Ad antiquitatem" or anteriority: if a family and a collective system had occurred somewhere, it can be considered to be a potentiality for the studied society; however, no information can be deduced from the absence of past anthropological rules. Thus, it is only a principle of probability allowing a past anthropological rule to be more likely present in the concerned society;

2. "Ad populum" or majority of the proximity: if a family and a collective system occurred in a neighboring culture and, even more, in the majority of neighboring cultures, it can be considered to be a potentiality for the studied society; 
however, no information can be deduced from the absence of this anthropological rule. Thus, and again, it is only a principle of probability allowing a past anthropological rule to be more likely present in the concerned society: it has happened that anthropological rules have appeared and/or crystallized in societies by cultural, ethnical or class opposition or other restrictive mechanisms artificially imposed by power holders;

3. "Primum non nocere": social information about past societies is so lacunar and flawed that we propose first to replace " obvious » or classical rules for a more "innocuous" functioning: for instance, choosing patrilineal systems for societies for which no social stratification has been observed through, for instance, funerary, differences, may appear the most evident rule by default. However, it creates such bias by producing social stratification between female and male heirs, thereby creating "naturally" social differentiation that we suggest adopting in the case of ignorance regarding such issues in a bilinear system;

\begin{tabular}{|c|c|c|c|}
\hline & anterior era & same era & posterior era \\
\hline Same territory & $\begin{array}{l}\text { (3) Manageable } \\
\text { environmental and technical } \\
\text { packages }\end{array}$ & (1) ideal situation & $\begin{array}{l}\text { (5) Manageable environmental } \\
\text { package. technical package to } \\
\text { be clarified }\end{array}$ \\
\hline Nearby territory & \multicolumn{3}{|c|}{ (2) extension based on the hypothesis of local homogeneity } \\
\hline $\begin{array}{l}\text { Other but ecologically } \\
\text { similar territory }\end{array}$ & $\begin{array}{l}\text { (6) Tendency for } \\
\text { environmental determinism }\end{array}$ & $\begin{array}{l}\text { (4) Tendency for } \\
\text { environmental } \\
\text { determinism }\end{array}$ & $\begin{array}{l}\text { (7) Tendency for environmental } \\
\text { determinism with less reliability } \\
\text { than (6) \& (7) }\end{array}$ \\
\hline $\begin{array}{l}\text { Other and ecologically } \\
\text { different territory }\end{array}$ & $\begin{array}{l}\text { (9) quasi no reliability: the } \\
\text { technical package may be } \\
\text { theoretically acceptable }\end{array}$ & $\begin{array}{l}\text { (8) quasi no reliability: } \\
\text { the technical package } \\
\text { may be theoretically } \\
\text { acceptable }\end{array}$ & (10) nearly useless \\
\hline
\end{tabular}

For rules regulating the connections between social and environmental components, i.e., the practices and techniques allowing humans to use and transform natural resources, we also hierarchize the reliability according to principles of anteriority and proximity; the latter applied to neighborhood for technologies and to ecological similarity for ecologically constrained factors. We then propose this succession of conditions from the most reliable until the least one:

1. The "best" source is of course the "same era, same territory" situation: data can then be obtained from directly concerned archaeological sources and extended to the whole concerned territory by inference and generalization. For instance, one may first suppose that Linear Band Keramik (LBK) families were enlarged multinuclear because of the multi-room elongated shape of their houses compared to contemporary cultures, and then extending this family system to the whole culture.

2. "same era, nearby territory": extension can also be used for technical capital based on the postulate that rural farming or hunting/gathering societies living nearby for enough time have access to an equivalent set of technologies: we can then suppose that the availability of a technology in nearby cultures may allow the presence of this technology within the concerned culture; however, the absence of a technology in all neighboring cultures suggests that it is less likely to see this technology in the concerned culture;

3. "anterior era, same territory": many exceptions do occur in the temporal progressivity of technical capital along history; however, the trend is largely in favor of temporal extension allowing posterior inclusion of previous practices and techniques, at least within the panel of possibilities available for simulated humans;

4. "Same era, other but ecologically similar territory": We use the term "ecologically" by integrating the manpower ratio compared to ecologically constrained needs, implying, for instance, that highly manpower-demanding weeding and watering steps in the farming cycle may be equivalent for both Khmer and Mayan forests, which can inform both the panel of practices and techniques available for the concerned society with a lower reliability than 2 and ecological "determinism" with a higher reliability than 2 if the latter concerns different but neighboring ecosystems. 
5. "Posterior era, same territory": to avoid anachronism, extension may be defined especially regarding ecological constraints according to the difference of technical capitals between the two periods, including social innovations such as manpower restrictions or, conversely, collective manpower mobilization: for an equivalent capacity of transformation of the territory, one may then use information such as a fruitful (and sometimes apparently obvious) restriction, for example, arid areas in the Middle east, even those close to large Mesopotamian rivers, were not irrigated beyond a certain extent even with the appearance of energy-multiplying techniques. Thus, socio-ecological models should consider areas such as those that are absolutely non-irrigable. However, we consider it to be less reliable than 4 because the diffusion / innovation of techniques has significantly more impact on the relations between society and nature than the variability of these relations among societies.

6. "Anterior era, other but ecologically similar territory": no information can be here deduced regarding the panel of practices and techniques available for the concerned society; however, such information may be helpful for the ecological semi- "determinism" regarding the use of natural resources. For instance, some practices regarding livestock in open territories, such as steppes and savannas, can be used, such as herding (how many animals for a shepherd), but not all of them, such as prolificacy.

7. "Posterior era, other but ecologically similar territory": the argumentation here is equivalent to 6 but; however, for the same reason as in the difference between 3 and 5 , it is far less reliable.

8. "Same era, other and ecologically different territory": here, the sole element to be integrated when no information is available is the maximum panel of technologies and practices to the extent that the two considered cultures had contact. If not, nothing can be said.

9. "Anterior era, other and ecologically different territory": Again, it is equivalent to the previous level, with less reliability.

10. "Posterior era, other and ecologically different territory": nothing can really be said.

Let us not forget that if we assume isotropy of rationality and ecology, i.e., that the present behavior of the system is related to the past, then we need to update the meaning of the available information, and it requires a sustained analysis and synthesis work and much reflection as the conditions under which the facts occurred were not, necessarily, in the same context in which they now occur ${ }^{3}$. Then, if we want to use the information of the present and the past to propose a future, then we must resort to forecasts whose methods have limitations that require such information to be conditioned. Behind all of this is the human being who directs the thought to build methods and models of information processing.

\section{Modelling take-off: piloting tricks}

\subsection{Initialization: avoiding initial distortion}

Agent-based models are temporally defined. At $\mathrm{t}=0$, whatever the length meaning of the timestep, and as many functions are evolution processes of the same simulated variables, these lasts should be initiated. Posing it a priori creates distortions and wide variations in the outputs of the first timesteps, especially if their values are very different from the variable average values. One may propose, as happens in KISS approaches (Edmonds and Moss, 2005), to wait for some timesteps by considering them to be non-valid; however, this distortion may remain even if the related distortion cannot be detected through, for instance, too large impacts on effect-accumulating biophysical factors, such as fertility. Finally, and more conceptually, history is a permanent process with no beginning; thus, seeing unhistorical fluctuations is very depreciative

\footnotetext{
${ }^{3}$ For instance, even if ecological conditions at the beginning of the Holocene were suitable in central Europe for many tree species present now, some species were absent due to the fact that they are actually alien, having come from the Americas or Asia, or they may have only been slowly recolonizing the continent from Mediterranean shores, which takes time.
} 
for the outputs' appearance from the point of view of thematicians. We then propose to reduce as much as possible the corresponding fluctuations by assuming, for instance, to calibrate initialization values as simple means deduced from the first simulation sets. One may then suggest measuring the stability of the solutions and designing a mechanism that helps control it before using the model for further explorations.

\section{2. "From the top of this pyramid, forty centuries look upon you" (Bonaparte, 1798)}

Courdier et al. (1998) describe the construction of a model as a spiral where modelers come back and forth on the various modules of the model through progressive adjustments. We adhere to this point of view; however, we consider that this can be reduced through the hierarchisation of modules because of inter-variable dependencies, from which the incidence of such dependencies should be evaluated. These dependencies are nested or more precisely structured in a pyramidal way (Figure 1). At the base of this pyramid of dependencies and therefore as the first basement bricks of the pyramid to construct, one should build independent abiotic factors, such as climate, topography, soils, river and shoreline movements as well as the range of present plant and animal species, from which we deduce their distribution and their spatial and temporal variability, the diachronic fertility of soils. On the next floor, and both deduced from the latter and combined with fixed rules, social structures and technical capital, we then construct the practices of natural resource uses (agriculture, animal husbandry, hunting, gathering, and fishing). On the next floor again, the dynamics affecting societies, affected by production activities' differential efficiencies, are elaborated, as much on the round run, the annual and generational cycles. Finally, on the last floor as the long run, one may complete the pyramid with the dynamics of stratification and separation/colonization.

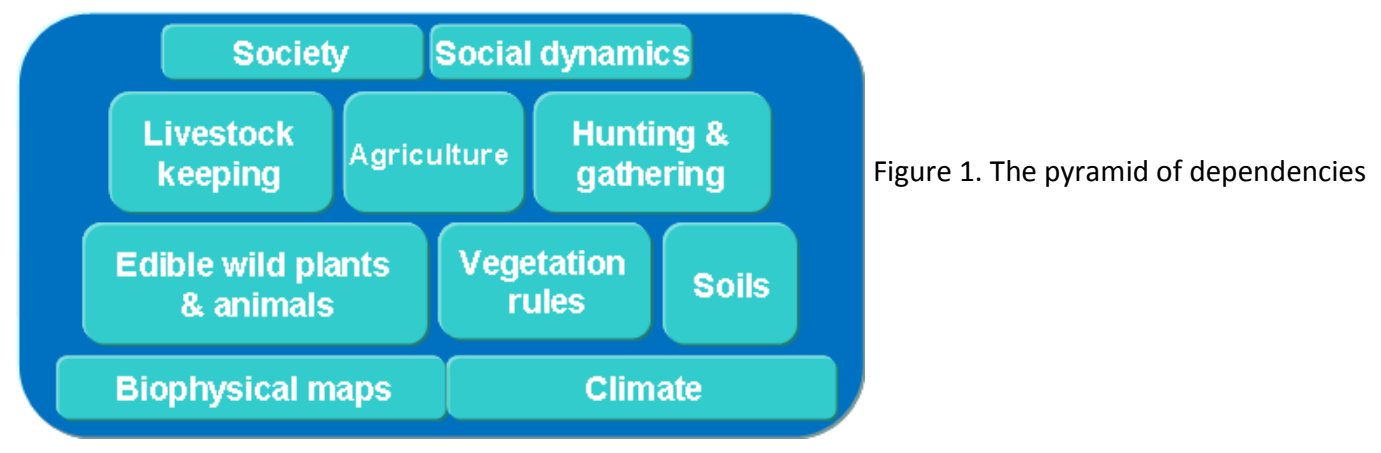

\subsection{The modelling process: an experimental demarche}

The model is only useful if it reflects not only the situation that one wishes to mimic or simulate but also the space of alternatives, reduced to a minimum to simplify the task but sufficiently broadened to answer the question at the origin of the model: only the robustness of a simulated answer along various parameter alternatives can show that this answer can be validated, even with fragile data.

It is then necessary to have confidence in this model, and this is only possible through a confidence-building test (not a real validation as it cannot exist, as described above) first through a calibration at the micro entity level ("does it work the way we want?"), then at the macro level ("do the environmental settings behave like we need?", does the population of this village behave along the constraints we planned?"), then the most important, the comparison with external data not used in the model (Erreur! Source du renvoi introuvable. left). Only then can the model serve as the bench of experiments, the test-bed to crush, modify, and tinker with the use of scenarios (Erreur ! Source du renvoi introuvable. right). We therefore make a call for modeling as an experimental approach.

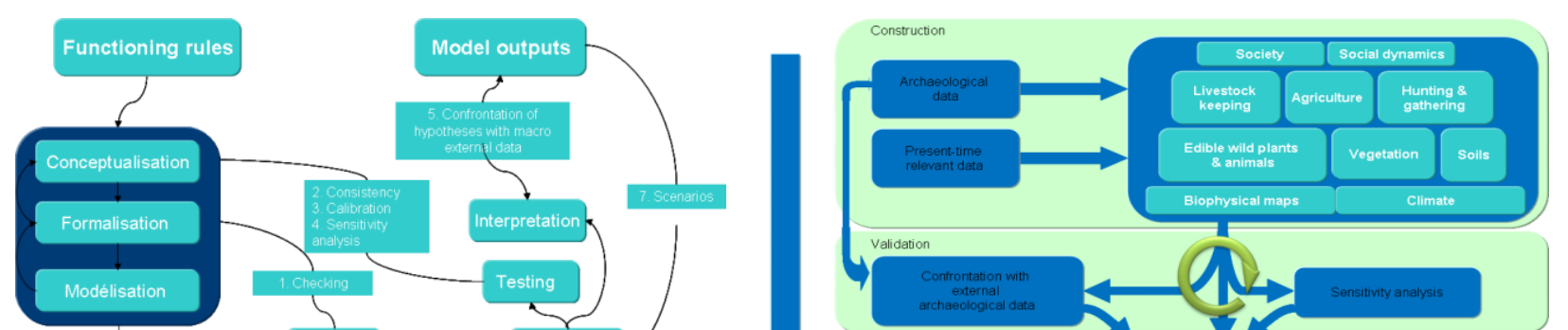


The scenarios described as the final but most proficient phase of modelling presented in Erreur! Source du renvoi introuvable. right must fulfil three steps:

- As part of the confidence-building steps, each scenario is actually an exploratory distortion of the average "businessas-usual" base scenario. However, as such models are always complex and are actually growing in complexity and heaviness over time, including many functions and many variables (Rubio-Campillo, 2015), a full sensitivity analysis soon becomes enormous following an exponential law. For instance, assessing a complete single-parameter sensitivity analysis on a model with 52 variables implies, with a minimum of 5 degrees of freedom and 20 simulations each, 5200 simulations. We therefore use a partial sensitivity analysis on the most relevant factors, according to the potentiality of the variability by which they occur, their weight in the model and the panel of the scientific disciplines they cover. One may then suggest using the faster Morris methodology (Morris, 1991) which provides parameters tendencies and qualitative rankings but cannot be used as a screening method (Ye and Hill, 2017).

- The base scenario itself is to be explored once confidence has been obtained through outputs comparison with nonincluded data by exploring simulation outputs on areas where no data have been acquired, for instance, in archaeologically unexplored zones: discovering remnants following simulation outputs is the best possible confirmation of such a model. Other ways include instantiating the model in a different geographic configuration and a different but similar culture to extend its genericness;

- The scenario exploration part, which can be considered to be a retroprospective demarche (Paegelow and Camacho Olmeido, 2008; Verhagen and Whitley, 2012) may follow two demarches:

- The reductio ad absurdum exploratory purpose: this implies using the model with voluntarily caricatured scenarios to invalidate hypotheses. Usually, such hypotheses are non-nuanced ones, for instance, climatedeterministic scenarios. Simulations may show that one simple reason is insufficient to explain the dynamics implying the acknowledgement and consideration of multifactorial combinations as often occurs;

- Finally, one may then use the model as a comparison among various legitimate hypotheses to determine which of the scenario simulation outputs best match the field data: no validation can be provided in that way; however, a plausibility-based hierarchisation can then be obtained.

\subsection{Integrating data: part margin of error, part variability}

Every piece of data obtained through measurements is entailed to a margin of error, especially if it concerns past issues. Even more, paleo-environmental or archaeological data are rare, and a statistical analysis on the variability of their values is thus difficult, apart from some repeatable data, such as the number of house poles or non-ritual everyday pottery patterns. For instance, palynology data providing temperature and rainfall reconstitutions from European Pollen Database sources (http://www.europeanpollendatabase.net/index.php) have a margin of error on these two variables. Transforming such data into adapted ones, i.e., at the month level and for each $\mathrm{km}^{2}$ of a territory, implies creating random monthly temperature and rainfall, necessitating a standard deviation for doing so. We thus used the margin of error as a maximum 
variability for a proxy of the standard deviations we needed, greatly increasing the range of extremes of the reconstituted climate. Such a rough procedure may be considered only in the invalidation-based experimental demarche through the caricature-then-nuance procedure described above. This point can be considered to be useful for elements of the social components of RSES, such as family size (using house size as a proxy), livestock size (using meat consumption as a proxy) or gender inequality (using grave wealth as a proxy).

\section{Social modelling difficulties}

\subsection{The scale gap}

Several examples of archaeological modelling face harsh issues when they must combine at the right scale the interactions among social elements. Indeed, the social component of RSES altogether implies the following:

1. The evolution of the technical and practical assets, i.e., all the components parameterizing all production and economic activities practiced and used by the concerned population for living; it then defines the differential productivity according to the systematically most rare resource, the manpower (except very rare preindustrial situations, such as ancient Egypt, where land was even rarer);

2. Data characterizing the demographic growth and variability according to food availability, the latter being defined due to economically, ecologically and socially related productivity;

3. Rules defining the conditions of accessibility of all family and group members to the different production activities and related products (various food), thereby defining the everyday hierarchy within human groups;

4. Rules of stratification including marriage, inheritance transmission rules and rights of use that allow the creation of inequalities is an important point as it can be compared to the social stratification of usually better conserved and less taphonomically altered graves as well as altering the most equal and more optimal use of manpower and gender distribution (for instance, through polygamy);

5. Rules of family and group splitting and geographical movements, defining the power of expansion of a village and its sensitivity to ecologically defined parameters through the temporally and spatially variable manpower productivity of all production and economic activities as well as the influence of non-ecological factors in the choice of new settlements, such as the force of the habitus, i.e., the variable definition of the preferred oekoumen according to the past history of the concerned social group.

Putting together all these elements in a single model is a challenge because they do not forcedly correspond to the same spatial scale: for instance, the level 1 may correspond to the culture as a whole and then, going deeper at the village level, one should integrate discrimination regarding the mastery of this technology (for instance, livestock herding). The level 5, because it should include both the departure and the arrival areas, may be implemented at a larger scale than the others. Anyhow, the more social factors are implemented, the more we require many villager agents to cover all the various cases of socio-ecological situations in the model, the more also each agent is complicated to model and to calibrate, the more the model requires time for implementation and simulations. One may then observe that agent-based models focus on some of these elements: For instance, the model of Premo (2006) on hunting-gathering Paleolithic groups focuses on the point 3, in this case the commensality within a group of humans. Most models can be classified into categories according to the scale that is itself related to the issue but also the underlying hypothesis (Saqalli and Baum, 2015): we then separate models into local scale models and large-scale models, which we describe through a non-exhaustive series of some examples:

- Within the local scale (i.e., the village or the group of villages), the famous founding work of Kohler, Axtell, Epstein, Janssen and others (Janssen et al. 2003; Janssen, 2009) on the Anasazi give priorities to points 2 and 3. The water constraint is so harsh that the resulting situation is de facto binary: if there were no water, the Anasazi people would 
not be able to survive. An equivalent model (Baum, 2014) explores the various practices regarding land use at the village level, thereby connecting 2 and 3.

- At the global level, GLUE (Wirtz and Lemmen, 2003) explores the transition to the Neolithic era through a transmissible set of techniques expanding through colonization and diffusionist patterns through the Ancient World, with a focus on certain areas and exploration of climate deterministic hypotheses (Lemmen and Wirtz, 2014), which we can translate into a combination of 2 and 5, explored through scenarios based on 5. The model of Conolly et al. (2008) analyses the diversity of the set of cropping plants and connects it to environmental perturbations and diffusion, meaning combining 1 and 5. The model of Bernabeu et al. (2015) addresses Neolithic expansion patterns, also combining 2 and 5.

A project (ANR Obresoc) with two divergent objectives, reconstituting the farming system of the LBK and the expansion then decline of this culture across time and space, was even forced to split it in portions with one focusing on the livestock and farming systems (Saqalli et al. 2014) and another on 5, the expansion itself.

As a consequence, we then call for the formalization of the positioning of the social component of the issue along at least two of the 5 points presented above, using one as an object of research and the other one as a subject to be explored (see $\S 2 \cdot 1)$.

\subsection{Social component affecting binaries}

This section tends to demonstrate the powerful impact social elements may have on modelling outputs:

- Inheritance and gender stratification: first, one may have to note that inheritance in a low demographic density context (regarding the density in relation to fertile lands) concerns only mobile assets, i.e., livestock, the large availability of lands reducing to zero the value of such lands. Whatever the gender-defined discrimination regarding inheritance, whether female or male heirs are advantaged, it creates de facto as social stratification which extent depends on the force of this discrimination. Let us suppose that this discrimination advantages males and is absolute, i.e., there is no part of the inheritance given to daughters and no dowry as compensation. Therefore, families of only daughters must distribute in other families their assets (through a lineage link or randomly) and cannot conserve a patrimony. However, sons-only families conserve their assets. A second case proposes a non-absolute discrimination (for instance, $2 / 3$ for sons and $1 / 3$ for daughters): with patrilocality married daughters bring their assets out of the family patrimony, "disadvantaging" their native families regarding patrimony conservation and advantaging their new ones. Gender natural variation may be considered as balancing the dynamic to keep equivalent gains and losses among families. However, luckily "advantaged" families and lineages, by having (still in our example) sons, both accumulate assets from spouses and create new family branches providing security to the whole lineage, compensating thereby the non-patrimony effect. Therefore, initial random differentiation keeps some lineages advantaged and distribution of transmission rights should be carefully under consideration: Todd (2011) proposes as a prior system before the great extension of the patrilocality a system of origin based on bilocality and bilinearity.

- Ultimogeniture vs. primogeniture: an equivalent discrimination phenomenon occurs between elders and juniors during transmission if a differentiation is defined. Moreover, this has an important effect on the power of expansion of a culture: Let us consider a theoretical case of families with all two children. The elder family has kids statistically older than the ones from the junior child. If this culture uses ultimogeniture, meaning it is the elder child who leaves, his/her children will come to age before the ones from the junior family and the manpower capacity of this family will be more rapidly higher. If there is a difference of 5 years between the two heirs, the child of the elder will come on age 5 years earlier. Each generation needing more or less 30 years, this implies a speed difference of $17 \%$ with only this anthropological difference; 
- Enlarged families/mononuclear families (Radja, 2003): this opposition is often forgotten as a major factor of reduction of the manpower constraint and thereby RSES productivity. We show in Saqalli et al. (2010a; 2010b; 2013) that the enlarged family configuration allows families to overcome manpower constraints thanks to family solidarity, for rapidly build houses, clear new fields, hunt, fish, gather and keep a large livestock herd at the same time for example. Mononuclear families are lowered in their expansion because of theses everyday constraints. However, we also show in the same articles that enlarged families are less robust to environmental shocks and variations and local famines have then far more consequences on demography. From then on, we do hypothesize that a major explanation for the difference between LBK families and equivalent contemporary and neighboring cultures such as the Starčevo culture can be seen in the configuration of houses: the long houses of the LBK are a reflection of enlarged households with many nuclear families while the Starčevo houses reflects the nuclear family type;

- Practices and geography: this relation leads to various results in terms of one activity efficiency and in pressure on resources according to its geographical configuration. For instance, we have shown in Van Vliet et al. (2010) that hunting through pathways creates de facto a game haven. As other examples, Rouchier et al. $(2000 ; 2001)$ and Maury (2004) have simulate the daily or yearly transhumance movements of herds at very local or at a medium range, showing topology plays a large role on the distribution of the pressure over land and resources.

\subsection{Round time functioning: production activities}

For all the economic activities linked to local resources (hunting, fishing, livestock, agriculture), the functions linking initial environment potential (such as fertility, climate productivity), human transformations (such as land clearing, burning, livestock-based fertility transfer) and cultural operations (soil preparation, amendments, seeding, weeding, harvesting) are to be characterized to produce yields varying spatially and fitting with literature estimates (Rowley-Conwy, 1981; Gregg, 1988; Mazoyer and Roudart, 1997; Ebersbach, 1999; 2004; Rösch et al. 2002; 2004; Kreuz et al. 2005; Bakels, 2009; Malézieux et al. 2009). The various economic activities envisaged are:

\subsubsection{Wood needs and cuttings}

Firewood harvesting is the least frequently discussed resource use practice, although according to Mazoyer and Roudart (1997), it requires a considerable amount of land, besides farming and pasture lands. However, as the only practice to be modelled is wood harvesting or cutting, modelling is not very complex. A program specifically dedicated to firewood (Antona et al., 2005; Bacaër et al. 2005) explores scenarios on timber harvesting in Sahelian Africa. Timber cutting is more complex: it must meet the specific demand for houses (or pirogues) and requires specific needs (some species specific to carpentry, a forest old enough and in a suitable place to shelter large trees...). To our knowledge, no modeling has integrated this aspect but its modelling, if considered justified, does not raise fundamental questions.

\subsubsection{Agriculture}

In addition to investigations on past agricultural systems, of which there are some examples such as Baum (2014), many models of non-industrial current farming systems may be used to analyze past rural populations and areas. They are more or less detailed and based on the hypothesis of an optimization of available resources, in particular manpower and land. As mentioned above, these simulations balance between models based on functions derived from correlations of available data and models in which processes are simulated. The former focus on spatial hypotheses about the evolution of these agrarian systems, and therefore work on larger territories, while the latter focus more on the impact of social factors, most often on small territories.

The former, when used to simulate phenomena that are highly spatialized and relatively independent of economic and/or social factors, allow a good reconstruction of the phenomena considered, more like GIS integrating cellular automaton functions (Lieurain, 1998; Berger and Schreinemachers, 2006; Henry et al. 2003). On a larger scale (a smaller territory), one can see Gibon et al. (2009) on the environmental responses to farm-level agro-farm level agro-sylvopastoral practices. The 
LUCC community, from which some examples such as Lambin et al. (2000; 2001), Parker et al. (2001) or Chang-Martínez et al. (2015), summarize the possibilities for understanding the co-evolution of vegetation cover and land use (Munroe and Müller, 2007). In particular, it stresses the importance of non-spatial factors (particularly non-biophysical) as determinants of this evolution, such as institutions. Generally speaking, the more the model is oriented towards the analysis of hypotheses involving a large territory, the less detailed the agricultural practices are.

As an intermediate step towards more social and de facto approaches in smaller territories, Bonaudo (2005) developed a multi-site, multi-activity model that introduced the arrival of new migrants along Amazonian routes and the evolution of their multi-crop-forest-breeding production systems during colonization as well as different family factors. The timestep is annual, and agricultural operations are reproduced in very simplified ways. Castella et al. (2005; 2007); Castella and Verburg (2007) discussed different scenarios for the evolution of Vietnamese mountain production systems based on family agents operating on several types of land and in several workshops. Finally, Saqalli et al. (2010a; 2010b; 2013) simulate several Sahelian agrarian systems based on the combination of polyculture and animal husbandry on a timestep of one week, allowing for the development of all the cultivation steps (the shortest cultural step being the sowing, of one week for a 1 ha plot, it is this timestep that was chosen) and, in particular, the revealing of link between the sequential management of the agricultural cycle with temporary labor constraints within the farm and temporally and spatially highly variable environmental constraints (rainfall delay, delayed sowing, rapid evolution of fertility).

\subsubsection{Livestock-keeping}

All the previous systems included livestock components to varying degrees depending on the nature of the corresponding production system. The chosen complexity or simplicity of the animal husbandry cycle is equivalent to the corresponding agricultural system. We refer to the previous section for work on multi-crop-livestock production systems. Several studies have focused specifically on animal husbandry:

Livestock herds can be represented in the form of flocks or individuals, or they can be represented virtually through their impact on pastures and contributions to the farms to which they belong (Landais, 1992; Bonnefoy et al. 2001). The interest in herd representation (family or linked to a "house," for example, in the case of villages simulated in this way) is simplicity: the herd agent can have specific attributes, for example, "number of individuals for each species". (Rouchier et al. 2001) explore the relationship between gifts and counter-gifts (Alam et al. 2005) to define transhumance systems not only governed by environmental rules (time and spatial adequacy between grazing quality and herd needs) but also by marriage and gift-based alliances. This approach is similar to that of Gibon et al. (2009), Le Page et al. (2013) or Bommel et al. (2010; 2014).

Several authors have detailed the herds, either to simulate the shedding of these herds (Maury, 2004), or to represent the complementarity of different species on the evolution of the landscape (Mechoud et al. 1998), or to detail the differentiated evolution of herds according to families (Saqalli, 2010a).

Livestock herds can be differentiated into species as required. Thus, Saqalli et al. (2010a; 2010b) separated the three species present on the Nigerien Sahel (goats, sheep and cattle) by characterizing them in terms of harvesting from plant resources (shrubs and herbs), their specific characteristics (mortality, mortality of young, fertility, resistance to reduced rations, growth but also genus). Similarly, Mechoud et al. (1998) detailed the behavior of cattle and horses, after detailed GPS monitoring in real conditions, to analyze the complementarity of their pastures in mountainous estivas.

The interest of differentiating species and characterizing them in their adaptation to their environment can be linked with the will to reveal changes in the distribution of these species between villages according to their characteristics. This differentiation raises the question of the level of detail desired to characterize the link between herds' dynamics and environmental resources (water source, herbaceous, leaves) as a system. It may include the transformation of both vegetation and herds, the adaptation of pastoral practices as a consequence. It may also involve transhumance, either 
latitudinally (Saqalli et al. 2010a) or by altitude (Mechoud et al. 1998), which implies simulating practices outside the village border, sometimes very far away.

Finally, the questions asked to simulate the domestication of livestock are equivalent to those for plant species: the appearance of domesticated, locally or "imported" species, the diffusion of this domestication, and the evolution of the species.

\subsubsection{Hunting}

Mathevet et al. (2003) make the link between the waterfowl population and hunting rights on the Camargue as well as among hunting pressure, availability of rural households and the hunting population. More successfully, a series of studies focused on the Cameroon-Gabonese forest, Bakam et al. (2001), studies the co-evolution between hunting pressure and wildlife hunted by Petri networks, the formalism of modelling "real" dynamic systems by networks of probabilities, the emergence effect and the importance of spatialization, which is emphasized in Bousquet et al. (2000) and Van Vliet et al. (2010). The first article simulates the impact of trapping based on traps that are moved regularly, while the second simulates the effect of a type of hunting called "hunting in front of oneself" or "meeting hunting" along family trails. Other collective (e.g., beaten) or individual (e.g., hunting) hunting practices remain to be considered.

The question of the link between environmental resources and wildlife population dynamics is equivalent to that of livestock. The spatial aspects of wildlife sustainability are of course accentuated for large fauna that require larger spaces.

\subsubsection{Fishing}

Several works have been developed to represent the functioning of a fishery (Bousquet 1994) or even to manage the fisheries' resources affected by this fishery, such as Soulié and Thébaud (2006). However, it appears that few modelling tests are available to simulate the fisheries-resource relationship itself outside Bousquet (1994). However, it may be possible to simulate the different types of fishing (line, trap, net) according to the same principles as hunting (see the section above).

\section{Social factors among research community as a conclusion}

We did not insist on the requirements of the agent-based modeling community for formal protocols tending to be the reference methodology in modeling such as the UML formalization for mutual comprehension (Rumbaugh et al. 2004) and the ODD protocol for publication (Grimm et al. 2006; 2010), nor some very common rationality modeling methods such as the Beliefs-Desires-Intentions (BDI) (Georgeff et al. 1999). We consider that these methods should be taken for granted as a convention within the research community.

However, our own observations support the idea that interdisciplinarity is not socially easy for scholars (Turner, 2002; Henrickson and McKelvey, 2002). Any research seeks a balance between data collection and formalization (without necessarily going through a computer version). The use of computer models is, before any simulation results, an exercise in formalizing these conceptual models. This exercise comes up against two points:

1. They are more easily shared when they are limited to one discipline, first of all because of difficulties in the dialogue between different disciplines: the polysemies and the implicit practices of each discipline are all sources of their own confusion. Many research projects have experienced serious difficulties as a result of this misunderstanding, which is obvious, normal and cannot be solved by simple goodwill: by default, we do not understand each other. Some methods make it possible to formalize relationships such as the ARDI method (Etienne et al. 2011) but involve time and can take up to a full-time week;

2. These difficulties are reinforced by the tacit integration of the limits and approximations specific to the practical exercise of each: we understand each other better between geographers when we speak of spatialized models with 
only simplified neighborhood dynamics, and approximations are recognized as normal. We understand each other better between hydrologists on hydro-models whose approximations on underground flows are recognized within the community but that we do not wish to have to explain in other communities. The same goes for archaeologists and paleo-environmentalists. Hence, there is a need to seek a compromise and not a consensus. The latter is becoming more inaccessible as more partners are included in research projects (the more people there are, the higher the conflict emergence probability will be). According to Nachi (2006), "a compromise is a process that develops between partners seeking to reach agreement at the price of some accommodations, modifications, and reciprocal concessions between competing interests." This relates to the question of domination based on financial, academic and institutional or affective power among the concerned research community, which should not be avoided but should preferably be formalized. More practically, publishing in one's discipline is socially, academically and professionally recognized: publishing elsewhere is a low reward effort, especially for disciplines whose associated journals have high impact factors;

3. Finally, more conceptually, no model combining several disciplines is a direct transposition of each of them: a global architecture is necessary for the coherence of the whole. However, this necessarily implies a simplification that is difficult to legitimize for each of the thematicians in their own community when publishing an article, which further reduces the value of involvement; even more, one cannot avoid the involvement of competent thematicians by a working method, such as "show your model, we will tell you if it is good": Regardless of how much time a modeler devotes to a particular discipline component to include it in a model, the time wasted but also the probability of error are much greater: the experience and knowledge of a domain by a discipline specialist is fortunately irreplaceable.

The models and the simulation are not cold instruments of prognosis since they reflect the human and professional qualities of those who formulated them and of those who use them. A model reflects the desire for knowledge and curiosity of the specialists and the simulation, and thus there is a need to consider what the model wants to express.

There is a palpable cognitive impasse. Many researchers (reinforced by media image) perceive science to be a collection of data, which comes back to the original idea of cultural cognition: According to the Cultural Cognition Project (http://www.culturalcognition.net/), science "refers to the tendency of individuals to conform their beliefs about disputed matters of fact (e.g., whether global warming is a serious threat; whether the death penalty deters murder; whether gun control makes society more safe or less) to values that define their cultural identities".

The difficulty is in building a true transdisciplinary approach beyond the emotional aspect. The latter has an impact on the question of the research question, the subject and the object of research: in short, the ability to question everything.

\section{References}

Abar S., Theodoropoulos G. K., Lemarinier P., O'Hare G. M. P. 2017. Agent Based Modelling and Simulation tools: A review of the state-of-art software. Computer Science Review. 24, 13-33. https://doi.org/10.1016/i.cosrev.2017.03.001 Alam S. J., Geller A., Meyer R., Woerth B. 2010. Modelling Contextualized Reasoning in Complex Societies with "Endorsements." Journal of Artificial Societies and Social Simulation. 13, 6.

Alam S. J., Hillebrandt F., Schillo M. 2005. Sociological implications of gift exchange in multi-agent systems. Journal of Artificial Societies and Social Simulation. 8.

Allen E., Falconer S., Hessam S., Barton M. C., Fall P. 2006. Modeling of agropastoral human activities using agent-based simulation. Springer, New York, USA.

Altaweel M. R. 2008. Investigating agricultural sustainability and strategies in northern Mesopotamia: results produced using a socio-ecological modeling approach. J. Archaeol. Sci. 35, 821-835. https://doi.org/10.1016/j.jas.2007.06.012 
Amblard F., Rouchier J., Bommel P. 2006. Evaluation et validation de modèles multi-agents. In: Amblard F., Phan D. (Eds.). Modélisation et simulations multi-agents: application pour les sciences de l'Homme et de la Société. Hermes, Paris, France. 103-140.

An L. 2012. Modeling human decisions in coupled human and natural systems: Review of agent-based models. Ecological Modelling. 229, 25-36. https://doi.org/10.1016/j.ecolmodel.2011.07.010

Antona M., Bah A., Le Page C., Mahamane A., Aboubacar I. 2005. Using multi-agent modeling for policy research: The case of fuelwood policy in Niger. In: CABM-HEMA. Conference on Multi-agent modelling for environmental management, Bourg Saint Maurice-Les Arcs, France.

Axelrod R. 2006. Advancing the art of simulation in the social sciences. In: Conte, R., Hegselmann, R., Terna, P. (Eds.). 1999. Simulating social phenomena. Berlin, Springer, 21-40. Updated version in Rennard J.P. (Ed.), Handbook of research on nature inspired computing for economy and management. Idea Group, Hersey, USA.

Axtel R. 2000. Why agents? On the varied motivations for agent computing in the social sciences. Center on Social and Economics Dynamics - The Brookings Institution, 17, 1-23. https://doi.org/10.1016/i.cep.2007.02.029

Bacaër N., Bah A., Mahamane A. 2005. Fuelwood harvesting in Niger and a generalization of Faustmann's formula. Comptes Rendus Biologies. 328, 4, 379-385.

Bakam I., Kordon F., Le Page C., Bousquet F. 2001. Formalization of a spatialized multi-agent model using coloured Petri nets for the study of a hunting management system. In: Rash J.L., Truszkowski W., Hinchey M.G., Rouff C.A., Gordon D. (Eds). Formal approaches to agent-based systems. FAABS 2000. Lecture Notes in Computer Science. 1871. Springer, Berlin Heidelberg, Germany.

Bakels C. C. 2009. The first millennia of agricultural landscape. In: Bakels C. (Ed.) The western European loess belt. Springer Netherlands, Dordrecht, the Netherlands, 89-98.

Batini C., Cappiello C., Francalanci C., Maurino A. 2009. Methodologies for data quality assessment and improvement. ACM Computing Surveys. 41, 16. https://doi.org/10.1145/1541880.1541883

Batty M., Torrens P.M. 2001. Modeling complexity: the limits to prediction. CyberGeo. 201. https://doi.org/10.4000/cybergeo.1035

Baum T.G. 2014. Models of wetland settlement and associated land use in South-West Germany during the fourth millennium B.C. Veget. Hist. Archaeobot. 23, 67-80.

Becker H. S. 1996. The epistemology of qualitative research. In: Jessor R., Colby A., Schweder R. A. Ethnography and Human Development: Context and Meaning in Social Inquiry. 53-71.

Berger T., Schreinemachers P. 2006. Creating agents and landscapes for multi-agent systems from random samples. Ecology \& Society. 11. 2.

Bergson H. 1911. L'Intuition philosophique. 5-11/04/1911, 5th Congress of Philosophy, Bologna, Italy.

Bernabeu Aubán J., Barton M. C., Gordó P. S., Bergin S. M. 2015. Modeling initial Neolithic dispersal. The first agricultural groups in West Mediterranean. Ecological Modelling. 307, 22-31. https://doi.org/10.1016/i.ecolmodel.2015.03.015

Beven K. 2002. Towards a coherent philosophy for modelling the environment. Proc. R. Soc. 458, 1-20.

Blecic I., Cecchini A. 2008. Design beyond complexity: possible futures-Prediction or design? (And techniques and tools to make it possible). Futures. 40, 537-551. https://doi.org/10.1016/i.futures.2007.11.004

Boero R., Squazzoni F. 2005. Does empirical embeddedness matter? Methodological issues on agent-based models for analytical social science. Journal of Artificial Societies and Social Simulation. 8.

Bommel P., Bonaudo T., Barbosa T., Bastos da Veiga J., Vieira Pak M., Tourrand J.-F. 2010. La relation complexe entre l'élevage et la forêt en Amazonie brésilienne : une approche par la modélisation multi-agents La relation complexe entre 
l'élevage et la forêt en Amazonie brésilienne : une approche par la modélisation multi-agents. Cahiers Agricultures. 19, 104111. https://doi.org/http://dx.doi.org/10.1684/agr.2010.0384

Bommel P., Dieguez F., Bartaburu D., Duarte E., Montes E., Pereira M., Corral J., Lucena C.J., Morales Grosskopf H. 2014. A further step towards participatory modelling. Fostering stakeholder involvement in designing models by using executable UML. Journal of Artificial Societies and Social Simulation. 17, 6.

Bousquet F. 1994. Des milieux, des poissons, des hommes: étude par simulations multi-agents. Le cas de la pêche dans le delta central du Niger. PhD. in Economics. Université Lyon 1, Lyon, France.

Bousquet F., Le Page C., Bakam I., Takforyan A. 2000. A spatially-explicit individual-based model of blue duikers' population dynamics : Multi-agent simulations of bushmeat hunting in an eastern Cameroonian village. Ecological Modelling. 138, 331346.

Bonaudo T. 2005. La gestion environnementale sur un front pionnier amazonien. PhD. in Agronomy, Institut National Agronomique Paris-Grignon, Paris, France.

Bonnefoy J.-L., Bousquet F., Rouchier J. 2001. Modélisation d'une interaction individus, espace, société par les systèmes multi-agents: pâture en forêt virtuelle. L'espace géographique. 1. 13-25.

Bouleau N. 2001. Modélisation et contre-expertise. APMEP. Paris, France, 462-468.

Brenner T., Werker C. 2007. A Practical Guide To Inference In Simulation Models, Papers on Economics and Evolution. Max Planck Institute of Economics Evolutionary Economics Group, Jena, Germany.

Carley K. M. 1996. Validating computational models. Carnegie Mellon University, Pittsburgh, USA.

Carrer F. 2013. An ethnoarchaeological inductive model for predicting archaeological site location: A case-study of pastoral settlement patterns in the Val di Fiemme and Val di Sole (Trentino, Italian Alps). Journal of Anthropological Archaeology. 32, 54-62.

Carozza L., Berger J. F., Burens-Carozza A., Marcigny C. 2015. Society and environment in Southern France from the 3rd millennium BC to the beginning of the 2nd millennium BC: 2200 BC a tipping point?. 2200BC-A climatic breakdown as a cause for the collapse of the old world? In TAGUNGEN DES LANDESMUSEUMS FÜR VORGESCHICHTE HALLE, BAND 12, p. 333-362

Castella J.-C., Boisseau S., Trung T. N., Quang D. D. 2005. Agrarian transition and lowland-upland interactions in mountain areas in northern Vietnam: application of a multi-agent simulation model. Agricultural Systems. 86. 3. 312-332.

Castella J.-C., Suan P. K., Quang D. D., Verburg Peter H., Thai H. C. 2007. Combining top-down and bottom-up modelling approaches of land use/cover change to support public policies: Application to sustainable management of natural resources in northern Vietnam. Land Use Policy. 24. 3. 531-545.

Castella J.-C., Verburg P. H. 2007. Combination of process-oriented and pattern-oriented models of land-use change in a mountain area of Vietnam. Ecological Modelling. 202, 3-4, 410-420.

Chang-Martínez L. A., Mas J.-F., Valle N. T., Torres P. S. U. 2015. Modeling Historical Land Cover and Land Use: A Review from Contemporary Modeling. ISPRS Int. J. Geo-Inf. 4, 1791-1812. https://doi.org/doi:10.3390/ijgi4041791

Chattoe E. 2000. Why is building Multi-Agent Models of social systems so difficult? A case study of innovation diffusion. 24th International Conference of Agricultural Economists (IAAE), Berlin, Germany.

Cioffi-Revilla C., Rouleau M. 2009. MASON RebeLand: An Agent-Based Model of Politics, Environment, and Insurgency! Annual Conference of the European Social Sciences Association, Brescia, Italy.

Conolly J., Colledge S., Shennan S. 2008. Founder effect, drift, and adaptive change in domestic crop use in early Neolithic Europe. Journal of Archaeological Science. 35, 2797-2804. https://doi.org/10.1016/j.jas.2008.05.006

Couclelis H. 2002. Modeling frameworks, paradigms, and approaches. Geographic information systems and environmental modelling. Prentice Hall, London, UK. 
Courdier R., Marcenac P., Giroux S. 1998. Un processus de développement en spirale pour la simulation multi-agents. L'Objet. 4, 73-86.

Deguet J., Demazeau Y., Magnin, L. 2006. Elements about the emergence issue: A survey of emergence definitions. Complexus. 3(1-3), 24-31.

Dolukhanov P., Shukurov A. 2003. Modelling the Neolithic dispersal in northern Eurasia. Documenta Praehistorica. 31.

Ducrot R., Botta A. 2009. Strategies to institutionalize companion modelling approaches. 18th World IMACS / MODSIM Congress. 2983-2990.

Ebersbach R. 1999. Modeling Neolithic agriculture and stock-farming at Swiss Lake shore settlements:-evidence from historical and ethnographical data. Archaeofauna: International Journal of Archaeozoology. 8, 115-122.

Ebersbach R. 2004. Agriculture, stock farming and environment: adaptation and change during the Neolithic lakeshore period (4300-2400 cal BC) in Switzerland. Antaeus 27, 287-292.

Ebersbach R., Schade C. 2004. Modelling the intensity of Linear Pottery land use: an example from the Märlener Bucht in the Wetterau Basin, Hesse, Germany. In: Ebersbach R., Schade C., (Eds.) Enter the past: the E-way into the four dimensions of cultural heritage. BAR International Series, Oxford, UK, 337-348.

Eco, U. 1990. The Limits of Interpretation. Indiana University Press, New Haven, USA.

Edmonds B., Moss S. 2005. From KISS to KIDS: an "anti-simplistic" modelling approach. Lecture Notes in Artificial Intelligence. 34, 130-144.

Epstein J. M. 1999. Agent-based computational models and generative social science. Complexity. 4, 41-60.

Etienne M. 2010. Acteurs, Ressources, Dynamiques et Interactions: Co-construction d'un modèle d'accompagnement selon la méthode ARDI : guide méthodologique. CIRAD Editions, Montpellier, France.

Etienne M. 2010. La modélisation d'accompagnement: Une démarche participative en appui au développement durable. Editions QUAE, Montpellier, France.

Etienne M., DuToit D., Pollard S. 2011. ARDI: a co-construction method for participatory modelling in natural resources management. Ecology \& Society 16, 44.

Franck U., Troitzsch K. G. 2005. Epistemological Perspectives on Simulation. Journal of Artificial Societies and Social Simulation. 8.

Georgeff M., Pell B., Pollack M., Tambe M., Wooldridge M. 1999. The Belief-Desire-Intention model of agency. In: Müller J., Rao A., Singh M. (Eds). Intelligent agents vs. Agents theories, architectures and languages. Springer Berlin Heidelberg, Germany. 1-10.

Gibon A., Sheeren D., Monteil C., Ladet S., Balent G. 2009. Modelling and simulating change in reforesting mountain landscapes using a social-ecological framework. Landscape Ecology. 25, 2, 267-285.

Gilbert, N., Troitzsch, K. 2005. Simulation for the social scientist. McGraw-Hill Education, New York, USA.

Graves D. 2011. The use of predictive modelling to target Neolithic settlement and occupation activity in mainland Scotland. J. Archaeol. Sci. 38, 633-656. https://doi.org/10.1016/i.jas.2010.10.016

Gregg S. A. 1988. Foragers and farmers: Population interaction and agricultural expansion in Prehistoric Europe. Prehistoric archaeology and ecology series. University of Chicago Press, Chicago, USA.

Grimm V., Berger U., Bastiansen F., Eliassen S., Ginot V., Giske J., Goss-Custard J., Grand T., Heinz S.K., Huse G., Huth A., Jepsen J.U., Jørgensen C., Mooij W. M., Müller B., Pe'er G., Piou C., Railsback S. F., Robbins A. M., Robbins M. M., Rossmanith E., Rüger N., Strand E., Souissi S., Stillman R. A., Vabø R., Visser U., De Angelis D. L. 2006. A standard protocol for describing individual-based and agent-based models. Ecological Modelling. 198, $115-126$. https://doi.org/10.1016/j.ecolmodel.2006.04.023 
Grimm V., Berger U., DeAngelis D.L., Polhill J.G., Giske J., Railsback S. F. 2010. The ODD protocol: A review and first update. Ecological Modelling. 221, 2760-2768. https://doi.org/10.1016/j.ecolmodel.2010.08.019

Hazelwood L., Steele J. 2004. Spatial dynamics of human dispersals: constraints on modelling and archaeological validation. J. Archaeol. Sci. 31, 669-679. https://doi.org/10.1016/i.jas.2003.11.009

Henrickson L., McKelvey B. 2002. Foundations of "new" social science: Institutional legitimacy from philosophy, complexity science, postmodernism, and agent-based modeling. Proceedings of the National Academy of Sciences. 99, 7288-7295. https://doi.org/10.1073/pnas.092079799

Henry S., Boyle P., Lambin E. F. 2003. Modelling inter-provincial migration in Burkina Faso, West Africa: the role of sociodemographic and environmental factors. Applied Geography. 23, 115-136.

Janssen M. A., Ostrom E. 2006a. Empirically Based, Agent-based models. Ecology \& Society 11, 24-37.

Janssen M. A., Ostrom E. 2006b. Governing Social-Ecological Systems. In: Janssen M.A., Ostrom E., Tesfatsion L. (Eds.), Handbook of Computational Economics. Elsevier. 1465-1509.

Janssen M. A. 2009. Understanding Artificial Anasazi. Journal of Artificial Societies and Social Simulation. 12, 13.

Janssen M. A., Kohler T. A., Scheffer M. 2003. Sunk-Cost Effects and Vulnerability to Collapse in Ancient Societies. Current Anthropology. 44, 722-728.

Janssen M. A., Scheffer M. 2004. Overexploitation of renewable resources by ancient societies and the role of sunk cost effects. Ecology \& Society. 9, 6.

Jonker C. M., Treur J. 2013. A Formal Approach to Building Compositional Agent-Based Simulations. In: Edmonds B., Meyer R. (Eds). Simulating Social Complexity: A Handbook. Springer Berlin Heidelberg, Germany, 57-94. https://doi.org/10.1007/978-3-540-93813-2 5

Kaplan J. O., Krumhardt K. M., Pfeiffer M., Davis B. A. S., Zanon M. 2012. From forest to farmland and meadow to metropolis: Integrated modeling of Holocene land cover change. 97th ESA Annual Meeting, Portland, USA.

Kieken H., Dahan A., Armatte M. 2003. Models and modelling processes: a critical step for an environmental research. Natures Sciences Sociétés. 11, 396-403.

Kohler T.A., Gumerman G. J. 2000. Dynamics in human and primate societies: agent-based modeling of social and spatial processes. Oxford University Press, Oxford, UK.

Kohler T. A., van der Leeuw S. E. 2007. The model-based archaeology of socionatural systems. Oxbow Books Ltd, Oxford, UK. Kohler T. A., Bocinsky K. R., Cockburn D., Crabtree, S. A., Varien M. D., Kolm K. E., Smith S., Ortman S. G., Kobti Z. 2012. Modelling prehispanic Pueblo societies in their ecosystems. Ecological Modelling 241, 30-41. https://doi.org/10.1016/j.ecolmodel.2012.01.002

Kreuz A., Marinova E., Schäfer E., Wiethold J. 2005. A comparison of early Neolithic crop and weed assemblages from the Linearbandkeramik and the Bulgarian Neolithic cultures: differences and similarities. Veget. Hist. Archaeobot. 14, $237-258$.

Lake M. W. 2015. Explaining the Past with ABM: On Modelling Philosophy. In: Wurzer G., Kowarik K., Reschreiter H. (Eds). Agent-based Modeling and Simulation in Archaeology. Advances in Geographic Information Science. Springer, Cham Lambin E. F., Rounsevell D. A. M., Geist H. J. 2000. Are agricultural land-use models able to predict changes in land-use intensity? Agriculture, Ecosystems \& Environment. 82, 1-3, 321-331.

Lambin E. F., Turner B. L., Geist H. J., Agbola S. B., Angelsen A., Bruce J. W., Coomes O. T., Dirzo R., Fischer G., Folke C., Goerge P. S., Homewood K., Imbernon J., Leemans R., Xiubin L., Moran E. F., Mortimore M. J., Ramakrishnan P. S., Richards J. F., Skanes H., Steffen W., Stone G. D., Svedin U., Veldkamp T. A., Vogel C., Jianchu X. 2001. The causes of land-use and land-cover change: moving beyond the myths. Global Environmental Change. 11, 261-269.

Landais É. 1992. Principes de modélisation des systèmes d'élevage. Approches graphiques. Les Cahiers de la recherchedéveloppement. 32: 82-95. 
Lemmen C., Wirtz K. W., Gronenborn D. 2009. Prehistoric land use and Neolithisation in Europe in the context of regional climate events. EGU General Assembly 2009.

Lemmen C., Khan A. 2012. A simulation of the Neolithic transition in the Indus valley. In: Climates, landscapes and civilizations. 22.

Lemmen C., Wirtz K. W. 2014. On the sensitivity of the simulated European Neolithic transition to climate extremes. Journal of Archaeological Science 51, 65-72. https://doi.org/10.1016/i.jas.2012.10.023

Le Page C., Bazile D., Becu N., Bommel P., Bousquet F., Etienne M., Mathevet R., Souchère V., Trébuil G., Weber J. 2013. Agent-based modelling and simulation applied to environmental management: a review. In: Edmonds B., Meyer R. (Eds). Simulating Social Complexity: A Handbook. Springer, Berlin Heidelberg, Germany, 499-540.

Lespez L., Carozza L., Berger J.-F., Kuzucuoglu C., Ghilardi M., Carozza J.-M., Vannière B., and the ArcheoMed team, 2016. Rapid climatic change and social transformations: Uncertainties, Adaptability and Resilience. In: Thiébault S., Moatti JeanPaul (eds.).The Mediterranean region under climate change: a scientific update, Marseille : IRD ; AllEnvi, 2016, p.35-45. ISBN 978-2-7099-2219-7.

Lieurain E. 1998. Couplage SIG-SMA-SGBD. CIRAD-Tera, Montpellier, France.

Livet P., Phan D., Sanders L. 2014. Diversité et complémentarité des modèles multi-agents en sciences sociales. Revue française de sociologie. 55, 689-729. https://doi.org/10.3917/rfs.554.0689

Malawska A., Topping C. J. 2016. Evaluating the role of behavioral factors and practical constraints in the performance of an agent-based model of farmer decision making. Agricultural Systems. 143, 136-146. https://doi.org/10.1016/j.agsy.2015.12.014

Malézieux E., Crozat Y., Dupraz C., Laurans M., Makowski D., Ozier-Lafontaine H., Rapidel B., de Tourdonnet S., ValantinMorison M. 2009. Mixing plant species in cropping systems: concepts, tools and models. A review. Agronomy for Sustainable Development 29, 43-62.

Maru Y. T., Alexandridis K., Perez P. 2009. Taking "participatory" in participatory modelling seriously. 18th World IMACS / MODSIM Congress, 3011-3017.

Mathevet R., Bousquet F., Le Page C., Antona M. 2003. Agent-based simulations of interactions between duck population, farming decisions and leasing of hunting rights in the Camargue. Ecological Modelling. 165, 107-126

Maury M. 2004. Modélisation de la divagation des troupeaux de bovins (M.Sc. Cognitive Sciences). Université Bordeaux II, Bordeaux, France.

Mazher A. K. 2001. Towards a unified approach to modeling and computer simulation of social systems. Part I: Methodology of Model Construction. Seuil, Paris, France.

Mazoyer M., Roudart L. 1997. Histoire des agricultures du Monde. Seuil, Paris, France.

Mechoud S., Hill D. R.C, Campos A., Orth D., Michelin Y., Poix C., L'Homme G., Carrere P., Lafarge M., Loiseau P., Micol D., Brun M., Dubuc F., Dumont B., Petit M., Coquillard P., Geugnot J., Teuma M. 2000. Simulation Multi-Agents de l'entretien du paysage par des herbivores en moyenne montagne. Proceedings of the SMAGET: Modèles et Systèmes Multi-Agents pour la Gestion de l'Environnement et des Territoires, Clermont-Ferrand, France.

Montmain J. Penalva J.-M. 2003. Choix publics stratégiques et systèmes sociaux : Etat de l'art sur les théories de la décision et méthodologies de l'approche système. LGI2P, Paris, France.

Minsky M. 1965. Matter, mind and models. In: Proc. International Federation of Information Processing Congress 1965, 1, 45-49.

Morris M. D. 1991. Factorial sampling plans for preliminary computational experiments. Technometrics 33, $161-174$. Munroe D. K., Müller D. 2007. Issues in spatially explicit statistical land-use/cover change (LUCC) models: Examples from western Honduras and the Central Highlands of Vietnam. Land Use Policy. 24, 521-530. 
Neuhauser C., Pacala S. W. 1999. An explicitly spatial version of the Lotka-Volterra model with interspecific competition. The Annals of Applied Probability. 9, 1226-1259.

Nachi M. 2006. Concept commun et concept analogique de compromis: un air de famille. Essai d'épistémologie pragmatique. SociologieS, Théories et recherches. http://sociologies.revues.org/3097

Ostrom T. M. 1988. Computer simulation: The third symbol system. Journal of Experimental Social Psychology. 24, 5, 381392. https://doi.org/10.1016/0022-1031(88)90027-3

Paegelow M, Camacho Olmedo M. T. 2008. Modelling environmental dynamics: Advances in geomatic solutions. Springer, Berlin Heidelberg, Germany.

Parker D. C., Berger T., Manson S. M. 2001. Agent-Based Models of Land-Use and Land-Cover Change : Report and Review of an International Workshop. LUCC Reports, 6. UC Irvine, Irvine, USA.

Patterson M.A., Sarson G.R., Sarson H. C., Shukurov A. 2010. Modelling the Neolithic transition in a heterogeneous environment. J. Archaeol. Sci. 37, 2929-2937.

Pipino Leo L., Lee Yang W., Wang R. Y. 2002. Data Quality Assessment. Communications of the ACM. 45, 4ve, 211-218.

Popper K.R., 1985. Conjectures et réfutations. La croissance du savoir scientifique. Payot, Paris, France.

Porter A.L., Roessner J.D., Cohen A.S., Perreault M. 2006. Interdisciplinary research: meaning, metrics and nurture. Research Evaluation. 15, 187-195. https://doi.org/10.3152/147154406781775841

Premo L. S. 2006. Exploratory agent-based models: towards an experimental ethnoarchaeology. Digital discovery: exploring new frontiers in human heritage. CAA. 29-36.

Radja K. 2003. La famille dans l'analyse économique: modélisation et représentations théoriques de la famille. Université Montesquieu Bordeaux IV, Bordeaux, France.

Rodgers J. L. 2016. Moving in parallel toward a modern modeling epistemology: Bayes factors and frequentist modeling Methods. Multivariate Behavioral Research. 51, 30-34. https://doi.org/10.1080/00273171.2015.1093459.

Rösch M., Ehrmann O., Hermann L., Schulz E., Bogenrieder A., Goldammer J.P., Hall M., Page H., Schier W. 2002. An experimental approach to Neolithic shifting cultivation. Veget. Hist. Archaeobot. 11, 143-154.

Rouchier J., Requier-Desjardins M. 2000. La modélisation comme soutien à l'interdisciplinarité en recherchedéveloppement. Une application au pastoralisme soudano-sahélien. Nature, Sciences \& Sociétés. 8, 61-67.

Rouchier J., Bousquet F., Requier-Desjardins M., Antona M. 2001. A multi-agent model for describing transhumance in North Cameroon: comparison of different rationality to develop a routine. Journal of Economic Dynamics and Control. 25, 527-559.

Rowley-Conwy P.A. 1981. Slash and burn in the temperate European Neolithic. In: Mercer R. J., Farming Practice in British Prehistory. Edinburgh University Press, Edinburgh, UK. 85-96.

Rubio-Campillo X. 2015. Large simulations and small societies: high performance computing for archaeological simulations. In: Wurzer G., Kowarik K., Reschreiter H. 2015. Agent-based modeling and simulation in archaeology. Advances in geographic information science. Springer, Vienna, Austria.

Rumbaugh J., Jacobson I., Booch G. 2004. The Unified Modeling Language Reference Manual, 2nd Edition. Pearson plc, London, UK.

Saqalli M., Bielders C. L., Defourny P., Gérard B. 2010a. Simulating rural environmentally and socio-economically constrained multi-activity and multi-decision societies in a low-data context: a challenge through empirical agent-based modeling. Journal of Artificial Societies and Social Simulation. 13.

Saqalli M., Gérard B., Bielders C. L., Defourny P. 2010b. Testing the impact of social forces on the evolution of Sahelian farming systems: A combined agent-based modeling and anthropological approach. Ecological Modelling. 221, $2714-2727$. 
Saqalli M., Bielders C. L., Defourny P., Gérard B. 2013. Reconstituting family transitions of Sahelian western Niger 19502000: an agent-based modelling approach in a low data context. CyberGeo. 634. https://doi.org/10.4000/cybergeo.25760

Saqalli M., Salavert A., Bréhard S., Bendrey R., Vigne J.-D., Tresset A. 2014. Revisiting and modelling the woodland farming system of the early Neolithic Linear Pottery Culture (LBK), 5600-4900 B.C. Veget. Hist. Archaeobot. 23, 37-50. https://doi.org/10.1007/s00334-014-0436-4

Saqalli M., Baum T. G. 2016. Pathways for scale and discipline reconciliation: Current socio-ecological modelling methodologies to explore and reconstitute human prehistoric dynamics. In: Barceló J. A., Del Castillo F. (Eds). Simulating prehistoric and ancient worlds. Springer Computational Social Sciences. Springer International Publishing, 233-255.

Saqalli M., Maestripieri N., Jourdren M., Saenz M., Maire E. 2017. Estimer un risque environnemental sur base d'enquêtes déclaratives spatialisées: une entrée exacte mais imprécise sur les variables caractérisant un problème: présentation via des enquêtes réalisées en Equateur, en Tunisie et au Laos. In : Gaille M. (Ed). Etablir la preuve d'une pathologie environnementale: enjeux épistémologiques et politiques. Quae Editions. Montpellier, France.

Saqalli M., Chakroun H., Mahé G. 2018. Légitimité des scénarios de gouvernance et métrique de soutenabilité. Rapport SICMED, Marrakech conference, Morocco.

Schulze J., Müller B., Groeneveld J., Grimm V. 2017. Agent-based modelling of social-ecological systems: achievements, challenges, and a way forward. Journal of Artificial Societies and Social Simulation. 20, 8.

Schutte S. 2010. Optimization and falsification in empirical agent-based models. Journal of Artificial Societies and Social Simulation. 13, 2.

Taber C. S.,Timpone R. J.1996. Computational modeling. Quantitative applications in the social sciences. 113. Sage, Thousand Oaks, London, UK.

Tipping R., Bunting M. J., Davies A. L., Murray H., Fraser S., McCulloch R. 2009. Modelling land use around an early Neolithic timber "hall" in north east Scotland from high spatial resolution pollen analyses. J. Archaeol. Sci. 36, $140-149$. https://doi.org/10.1016/i.jas.2008.07.016

Todd E. 2011. L'origine des systèmes familiaux Tome 1: l'Eurasie. Gallimard, Paris, France.

Soulié J.-C., Thébaud O. 2006. Modelling fleet response in regulated fishery: an agent-based approach. Mathematical and Computer Modelling. 44, 5-6, 553-564.

Turner B. L. 2002. Contested identities: Human-environment geography and disciplinary implications in a restructuring academy. Ann. Assoc. Am. Geogr. 92, 52-74.

Van Gigch J. P. 1993. Metamodeling: The epistemology of system science. Systems practice. 6, 251-258.

Van Vliet N., Milner-Gulland E.J., Bousquet F., Saqalli M., Nasi R. 2010. Effect of small-scale heterogeneity of prey and hunter distributions on the sustainability of bushmeat hunting. Conservation Biology. 24, 1327-1337.

Verburg P. H., Schot P. P., Dijst M. J., Veldkamp A. 2004. Land use change modelling: current practice and research priorities. GeoJournal. 61, 4, 309-324.

Verhagen H., Smit R. 2003. Multi-agent system as simulation tools for social theory testing. 1-9.

Verhagen P., Whitley T. G. 2012. Integrating archaeological theory and predictive modeling: a live report from the scene. $J$ Archaeol Method Theory. 19, 49-100.

Wirtz K.W., Lemmen C. 2003. A global dynamic model for the Neolithic transition. Climatic Change. 59, 333-367.

Youngblood D. 2007. Interdisciplinary studies and the bridging disciplines: a matter of process. J. Res. Pract. 3, M18.

Ye M., Hill M. C. 2017. Global sensitivity analysis for uncertain parameters, models and scenarios. In: Petropoulos G., Srivastava P. K. (Eds.), Sensitivity Analysis in Earth Observation Modelling. 177-210.

Wolfram S. 2002. A new kind of science. Wolfram Media, Champaign, USA. 
Yu Y., Guo Z., Wu H., Finke P. A. 2012. Reconstructing prehistoric land use change from archaeological data: Validation and application of a new model in Yiluo valley, northern China. Agr. Eco. Env. 156, 99-107. https://doi.org/10.1016/i.agee.2012.05.013. 